\title{
Charlson Comorbidity Index: A Critical Review of Clinimetric Properties
}

\author{
Mary E. Charlson ${ }^{\text {a }}$ Danilo Carrozzino $^{\text {b Jenny Guidi }}{ }^{\text {b Chiara Patierno }}{ }^{\text {b }}$ \\ aDivision of Clinical Epidemiology and Evaluative Sciences Research, Department of Medicine, Weill Cornell \\ Medicine, New York, NY, USA; 'Department of Psychology “Renzo Canestrari," University of Bologna, Bologna, Italy
}

\section{Keywords}

Comorbidity · Clinimetric properties · Indices · Prognosis .

Sensitivity

\begin{abstract}
The present critical review was conducted to evaluate the clinimetric properties of the Charlson Comorbidity Index $(\mathrm{CCl})$, an assessment tool designed specifically to predict long-term mortality, with regard to its reliability, concurrent validity, sensitivity, incremental and predictive validity. The original version of the $\mathrm{CCl}$ has been adapted for use with different sources of data, ICD-9 and ICD-10 codes. The interrater reliability of the $\mathrm{CCl}$ was found to be excellent, with extremely high agreement between self-report and medical charts. The $\mathrm{CCl}$ has also been shown either to have concurrent validity with a number of other prognostic scales or to result in concordant predictions. Importantly, the clinimetric sensitivity of the $\mathrm{CCl}$ has been demonstrated in a variety of medical conditions, with stepwise increases in the $\mathrm{CCl}$ associated with stepwise increases in mortality. The $\mathrm{CCl}$ is also characterized by the clinimetric property of incremental validity, whereby adding the $\mathrm{CCl}$ to other measures increases the overall predictive accuracy. It has been shown to predict long-term mortality in different clinical populations, including medical, surgical, intensive care unit (ICU), trauma, and cancer patients. It may also predict in-hospital mortality, al-
\end{abstract}

karger@karger.com www.karger.com/pps

Karger $\stackrel{\text { ' }}{5}$

GOPEN ACCESS
(C) 2022 The Author(s)

Published by S. Karger AG, Basel

This is an Open Access article licensed under the Creative Commons Attribution-NonCommercial-4.0 International License (CC BY-NC) (http://www.karger.com/Services/OpenAccessLicense), applicable to the online version of the article only. Usage and distribution for commercial purposes requires written permission. though in some instances, such as ICU or trauma patients, the $\mathrm{CCl}$ did not perform as well as other instruments designed specifically for that purpose. The $\mathrm{CCl}$ thus appears to be clinically useful not only to provide a valid assessment of the patient's unique clinical situation, but also to demarcate major diagnostic and prognostic differences among subgroups of patients sharing the same medical diagnosis.

(c) 2022 The Author(s).

Published by S. Karger AG, Basel

\section{Introduction}

The term comorbidity has a Latin origin and results from the combination of two words: "co" meaning "along with" and "morbus" meaning "disease." It was Alvan R. Feinstein who provided the first clinical definition of this concept, which refers to "any distinct additional clinical entity that has existed or that may occur during the clinical course of a disease that is under study" [1]. Further, he noted that a comorbid condition has the potential not only to impact a patient's prognosis, but also to alter therapeutic plans and outcomes [1]. Prior to his paper, comparability of patients was judged primarily on similarities in age, gender, race, and anatomic stage and not on comorbid conditions. Since this resulted in comorbid conditions confounding outcomes, failure to catalog it led to 
the exclusion of patients with any diseases other than the index disease from studies.

The term "comorbidity" has been defined in many different ways [2]. The specific reason for defining a comorbid condition is crucial and there is no universally correct answer. Most agree that comorbidity is not a measure of overall health status, self-rated health, performance status (NY Heart Association criteria, Eastern Cooperative Oncology Group), psychological well-being, or stage of disease (i.e., Tumor-Node-Metastasis - TNM classification). Some measures have counted body systems involved or medications.

Central to the definition of a comorbid condition is the question: For what purpose? Co-occurrence is not sufficient to define a comorbid condition. If co-occurrence is the only criterion to define a comorbid condition, then color blindness, hangover, upper respiratory infection, an injured ankle after a car accident, pain in the thumb, and an elevated white blood cell count, would all be comorbid conditions.

The definition of a comorbid condition depends on the key questions involved: diagnostic comorbidity (conditions that confound diagnosis), treatment comorbidity (conditions that alter therapy), and prognostic comorbidity (conditions that impact outcomes). Diagnostic and treatment comorbidity must be defined in the context of a specific condition(s). In medicine, most major diseases are defined by specific criteria independent of the presence of another chronic disease, although the actual criteria may differ by groups or settings.

Diagnostic comorbidity is more complex in psychiatry than in medicine. In psychiatry, diagnostic comorbidity, even with the Diagnostic and Statistical Manual of Mental Disorders (DSM) handbook to improve inter-observer reliability, is a complex issue and considers a number of potential relationships between disorders: (a) one specific disorder preceding or increasing the risk for another one, (b) two coexisting disorders that may predispose to the development of another disease, (c) antecedent factors specific for different disorders, and (d) a complex interaction of one or more distinct antecedent factors [3]. This was shown in a 12-month study of 9,300 adults [4]; of the 2,500 adults who had one DSM-IV disorder, almost half $(45 \%)$ had more than two more DSM-IV disorders [4]. This complexity resulted in the development and promulgation of psychometric methods of assessment of psychiatric scales. In psychiatry, psychometrics has dominated assessments of disease [5]. Psychometric analytics used strategies for assessment such as Cronbach's alpha, where more items in the scale lead to higher correlations
[5]. Fava and Bech $[5,6]$ pointed out the difference between psychometrics and clinimetrics in psychiatry, and the clinimetric properties of existing and widely used measures were examined [7]. Fava et al. [3, 8] raised the issue that patterns of symptoms, severity of illness, timing of disease, rate of progression, response to treatment or impact of conditions are often not considered in the usual taxonomy of psychiatry.

Wright and Feinstein [9] pointed out that psychometric and clinimetric scales had different purposes. For psychometric scales, a number of homogeneous items for assessing the diagnosis of a single condition may be important, but for measuring a phenomenon like change in status or more complex phenomena, the index cannot be homogeneous and redundant [9]. Clinimetrics is the term originally coined by Alvan R. Feinstein [10] to introduce an innovative approach that has been redefined as the science of clinical measurements [11]. Such a clinically based evaluation method is particularly useful for testing a number of measurement properties (e.g., interrater reliability, concurrent validity, sensitivity, incremental, and predictive validity). This paper will focus on the clinimetric assessment of prognostic comorbidity, which is a broader concept than diagnostic or treatment comorbidity, and specifically on chronic conditions that impact on survival outcomes, especially long-term survival. Comorbidity has also been used to predict a variety of outcomes: functional status, quality of life, complications, readmissions, and health care utilization [12]. Kaplan and Feinstein [13] proposed an innovative method for classifying and staging comorbidity in relation to long-term survival. They focused on cogent comorbid conditions excluding such conditions as varicose veins and hemorrhoids, as well as completed illnesses such as previous fracture, and evaluated hypertension, congestive heart failure (CHF), or myocardial infarction (MI), stroke, pulmonary insufficiency, renal disease, chronic liver disease, gastrointestinal bleeding, amputation, cancer, alcohol, or physical impairment on a grade 1-3 scale, assigning 3 to patients who had a 3 in any of the areas. The 5 -year mortality rates for new onset diabetics range from $7 \%$ for patients with grade 0 to $69 \%$ for those with grade 3 [13]. Subsequently, the Charlson Comorbidity Index (CCI) developed in 1987 became the most widely used index, and is often considered to be the gold-standard measure to assess comorbidity in clinical research [14].

The present critical review was conducted to evaluate the clinimetric properties of the CCI, including reliability, concurrent validity, sensitivity, incremental validity, and predictive validity. 


\section{Methods}

In view of the amount of literature on this topic (e.g., the number of citations of the original version of the CCI exceeds 36,925 on Scopus, accessed on September 30,2021), this review cannot be systematic. We will analyze the most relevant studies concerned with its reliability, concurrent validity, sensitivity, incremental and predictive validity.

\section{Search Strategy}

A comprehensive search of the literature was performed using the following databases: MEDLINE, Embase, PsycINFO, PubMed, ScienceDirect, Scopus, and Web of Science. Each database was searched from inception to September 30, 2021. A manual search of the literature was also conducted, and reference lists of the retrieved articles were examined for further studies not yet identified. Further, the articles citing the original study [14] in the Web of Science were also considered to identify further potentially relevant studies. The search terms used were "comorbidity index," "reliability," "reproducibility," "concurrent validity," "predictive," and "mortality."

\section{Eligibility Criteria}

To be included in this review, studies had to meet the following criteria: (1) English-language article published in a peer-reviewed journal; (2) the full text of the article was available; (3) the article was an original study (e.g., research article, meta-analysis); (4) the study evaluated the clinimetric properties of the CCI or used a clinimetric approach to analyze the measurement properties of its different versions.

\section{Study Selection}

Three reviewers (C.P., D.C., and M.E.C.) independently performed the search, screened titles and abstracts, selected studies, evaluated the full text of articles appearing potentially relevant, and extracted data from studies meeting the eligibility criteria. In case of disagreement, a consensus was reached through discussion.

\section{Results}

The initial search of the literature yielded a total of 36,925 articles, but only those studies which best displayed the clinimetric properties of the various versions of the CCI were included and analyzed in this critical review. The different versions of the CCI have been extensively used in a wide range of medical settings and were found to entail the clinimetric properties of reliability, concurrent validity, sensitivity, incremental and predictive validity.

\section{The CCI}

The original version of the Comorbidity Index ( $\mathrm{Ta}-$ ble 1) developed by Mary E. Charlson consisted of 19 items corresponding to different medical comorbid conditions [14] displaying different clinical weights on the
Table 1. The CCl: the 19 item-version

\begin{tabular}{ll}
\hline Conditions & $\begin{array}{l}\text { Assigned weights } \\
\text { for each condition }\end{array}$ \\
\hline MI & 1 \\
CHF & 1 \\
Peripheral vascular disease & 1 \\
Cerebrovascular disease & 1 \\
Dementia & 1 \\
Chronic pulmonary disease & 1 \\
Connective tissue disease & 1 \\
Ulcer disease & 1 \\
Mild liver disease & 1 \\
Diabetes & 1 \\
Hemiplegia & 2 \\
Moderate or severe renal disease & 2 \\
Diabetes with end organ damage & 2 \\
Any tumor without metastasis & 2 \\
Leukemia & 2 \\
Lymphoma & 2 \\
Moderate or severe liver disease & 3 \\
Metastatic solid tumor & 6 \\
AIDS & 6
\end{tabular}

$\mathrm{Ml}$, myocardial infarction; $\mathrm{CHF}$, congestive heart failure.

basis of the adjusted risk of 1-year mortality, controlling for severity of illness of 559 patients admitted to the general internal medicine service (i.e., New York HospitalCornell Medical Center). The 19 conditions and associated weights, combined with age, were used to predict mortality of 685 patients with breast cancer from comorbid disease over 10 years [14]. The total score of the CCI consists in a simple sum of the weights, with higher scores indicating not only a greater mortality risk but also more severe comorbid conditions [14]. The CCI was developed to be used in different populations as a prognostic measure in longitudinal studies to predict mortality [14].

\section{Different Adaptations of the CCI for Use with \\ Different Data Sources}

Over the years, several adaptations of the CCI for use with different sources of data have been proposed for coding medical records, electronic health records (EHR), problem lists and ICD-9 and ICD-10 data, and different versions have been developed and come into use [15-19].

Age-Comorbidity Index

The Age-Comorbidity Index (age-CCI) was designed for use in small studies and was a highly significant predictor of mortality $[14,15]$. The age-CCI has been most
10

Psychother Psychosom 2022;91:8-35 DOI: $10.1159 / 000521288$
Charlson/Carrozzino/Guidi/Patierno 
often used in oncology. In 5,643 patients with colorectal cancer, the age-CCI predicted survival over 5 years [20], as well as perioperative and 18-month mortality in a smaller study of 279 patients [21]. The age-CCI predicted 5 -year mortality in 2,257 patients with gastric cancer [22] and 379 patients with resected pancreatic cancer [23]. The age-CCI predicted 10-year mortality in 1,598 men with prostate cancer [24], 793 patients with ovarian cancer [25], and 567 patients with advanced ovarian cancer who had debulking surgery [26]. In 4,508 lung cancer patients, the age-CCI was a better predictor of 3-year mortality than either the CCI alone or the Elixhauser index [27]. In 698 patients with resected renal cell cancer, the age-CCI better predicted long-term mortality than the CCI [28]. In 1,132 women with early endometrial cancer, the age-CCI predicted 4-year survival [29].

The age-CCI has also been used in other types of patients. In 1,057 hip fracture patients, the age-CCI was the most significant predictor of 5-year survival [30] and in 142 patients undergoing revision hip arthroplasty, the age-CCI predicted 2-year survival [31]. In 515 incident dialysis patients, the age-CCI predicted 15 -month mortality [32]. In 529 patients who had emergency general surgery, the age-CCI predicted 30-day survival [33].

\section{Adaptations of the CCI Using ICD-9 Codes}

Deyo et al. [16] proposed the first modified version of the CCI assessed through the application of ICD-9 diagnostic codes using fairly strict criteria. As Romano et al. [18] noted, Dartmouth-Manitoba created an ICD-9 interpretation using more ICD-9 codes. Not surprisingly, when the Deyo and Dartmouth-Manitoba versions were directly compared, the Deyo CCI scores were lower; however, the Deyo and Dartmouth-Manitoba CCI versions still had 90\% agreement, and 95\% agreement within one CCI point [34]. Both the Deyo and Romano adaptations had quite similar predictions of 6-month mortality in medical and surgical patients [35]. Roos et al. [36] also found that the Dartmouth-Manitoba Index was a significant predictor of 1-year mortality after coronary artery bypass graft $(\mathrm{CABG})$, pacemaker, or hip fracture surgery. Along similar lines, Khan et al. [37] translated the comorbidity index into the Read/OXMIS codes used in British primary care. D'Hoore et al. [38] adapted the comorbidity index to ICD9 using only the first three codes of ICD-9 and showed it predicted inpatient death in 62,456 patients with one of four medical conditions [39]. However, D'Hoore did not fare as well as the Deyo or Romano versions in direct comparison of prediction of 1-year mortality in 141,161 participants enrolled in epidemiologic studies [40].

Charlson Comorbidity Index
Adaptations of the CCI Using ICD-10

Sundararajan et al. [19] adapted the Deyo version of CCI for use with ICD-10 codes, classifying the CCI for more than 400,000 patients hospitalized in each of 4 years, in comparison to 2 years of ICD- 9 codes, as a predictor of in-hospital death. Using the area under the receiver operating characteristic (ROC) curve as a measure of the CCI's ability to discriminate between those subjects who experienced the outcome of interest (i.e., in-hospital mortality) and those who did not [41], Sundararajan et al. [19] showed that ROC values for the revised CCI were found to range from 0.85 to 0.86 . Halfon et al. [42], using clinical judgment, also mapped the Deyo adaption to ICD-10 codes, with codes that differ somewhat from Sundararajan's to study readmission of 3,473 Swiss patients (finding that comorbidity predicted readmission).

Quan et al. [43] took both the Halfon and Sundararajan codes and added a third list developed by coders to formulate a new set of ICD codes in 158,805 patients discharged in Calgary in 1 year; their ICD-10 CCI map had a statistic of 0.845 for in-hospital mortality [43]. Translating the ICD- 9 codes used by the Deyo and DartmouthManitoba CCI versions to ICD-10 codes by using a World Health Organization ICD-9 to ICD-10 translator [44], Nuttall et al. [45] compared their performance in ICD-10 and found small differences in performance between Deyo and Dartmouth (Deyo $c=0.71$; Dartmouth, $c=$ 0.73 ) in predicting inpatient mortality.

The Halfon, Sundararajan, and Quan ICD-10 versions of the CCI were compared in one paper using different numbers of patients between 225,000 in Japan and 37,057 in Switzerland and the distribution of scores was similar across the different versions [46]. The ROC curve for predicting in-hospital mortality was higher for the Quan and Sundararajan versions than Halfon [46].

\section{Inter-Rater Reliability of Data from Different Sources: Self-Report, Interview, or Medical Chart}

The clinimetric property of inter-rater reliability refers to the degree of agreement or concordance between different raters assessing the same clinical phenomena using different methods [47]. Waite et al. [48] were among the first authors who evaluated the inter-rater reliability of the original version of the CCI; they found a $58 \%$ absolute agreement in CCI scores across five trained raters with a $99 \%$ agreement if the difference was only a weight of one [48]. Hall et al. [47] also evaluated inter-rater reliability of CCI assessed by four separate raters in 40 patients with

Psychother Psychosom 2022;91:8-35 DOI: $10.1159 / 000521288$ 
head and neck cancer finding an intra-class correlation coefficient (ICC) of 0.80. Bernardini et al. [49] showed a kappa of 0.93 for two raters of CCI in dialysis patients.

\section{Self-Report versus Chart}

Different self-reported versions have been compared to data obtained from medical charts [50]. Katz et al. [17] created a self-reported questionnaire that had excellent agreement with chart-extracted data in 170 patients (ICC $=0.92$ ). Molto and Dougados [51] found high test-retest reliability (ICC $=0.94$ ) for self-report compared to chart review. Olomu et al. [52] found that the self-report and the chart version were closely equivalent. However, in one study [53] more conditions were reported by interviewers than in charts $(\mathrm{ICC}=0.51)$.

\section{Chart Review versus Discharge Summary and}

Problem Lists

Medical chart data provided more complete data about the CCI than hospital discharge data; thus, discharge data underestimated total comorbidity [54]. Swartz et al. [55] also found that discharge data only had half the chronic conditions as medical records. In contrast, discharge data were found to have more conditions and more accurately predict mortality than Medicare-linked Surveillance, Epidemiology and End Results (SEER) data [56]. However, chart review had higher specificity but poorer sensitivity for conditions in the CCI than EHR index-based problem lists (kappa $=0.23$ ), resulting in significant failure to accurately predict mortality in 1,596 men with prostate cancer over 15 years [57].

\section{Self-Report versus Claims Data}

The largest study of self-reported data versus claims data evaluated 7,761 patients admitted to a medical service over 4 years, and found that the area under the curve (AUC) for self-reported and ICD-9 diagnosis at the time of admission and the ICD-9 diagnoses over the year antecedent to admission were quite similar in predicting 1 -year mortality ( $c=0.70 ; c=0.73$, respectively) [58]. Zhang et al. [59] also found that both claim-based adjustment and survey-based adjustment resulted in similar predictions ( $c=0.702$ and $c=0.704$, respectively) of 2 -year mortality in 30,000 Medicare patients. On the other hand, agreement between self-report and 12 months of administrative data was poor in 520 emergency department patients [60].

\section{Chart versus Claims Data}

A review of seven papers comparing chart data with administrative data suggested that the claims data underestimated the CCI by 1 point [61]. Kieszak et al. [62] compared data extracted from charts versus ICD-9 codes for Medicare beneficiaries and found many more diagnoses on the charts, and that improved prediction of inpatient and 30-day mortality. In men who had prostatectomy, claims data underestimated CCI compared to chart data [63]. Quan et al. [64] showed that from the CCI, 4 conditions had similar prevalence between chart and administrative data; 10 had a lower prevalence in claims, and 3 had a higher prevalence [64]. For intensive care unit (ICU) patients, Li et al. [65] also found more comorbid illnesses by chart review than were coded in administrative data for ICU patients. Thygesen et al. [66] evaluated the positive predictive value of ICD-10 by reviewing charts, and found that overall positive predictive values were $98 \%$.

However, there are some international differences; in 2,464,395 hospitalized Chinese adults, the discharge diagnosis-based CCI was a significantly better predictor of inhospital mortality than the ICD-10 administrative data (kappa varied by specific condition) [67]. In 959 patients admitted to an ICU in Norway, the CCI from chart and administrative data were significantly correlated $(r=$ 0.667), but the CCI from charts was more complete [68]. When conditions coded by the Deyo version of ICD-9 were compared to those found in 1,200 patients in a chart review, the agreement was quite high (weighted $\kappa=0.71$ ), but comorbidity was underreported in administrative data [64]. Newschaffer et al. [69] (who also compared Kaplan-Feinstein and Satarino) found in 404 breast cancer patients that the inter-rater agreement was high $(\kappa=$ 0.945) using either records or claims, but claims had fewer data than records. In 524 hospitalized adults, van Doorn et al. [70] also showed that chart-based scores differed from scores derived from claims data. In contrast, in 890 Swiss patients administrative data were more complete than single day chart review [71].

\section{More Years and Reliability}

Lee et al. [72] showed that in 1,808 hospitalized adults, adding prior years administrative data on comorbidity improved prediction of 1-year mortality. Increasing the "look-back" interval for ascertaining comorbid diseases improved accuracy $[55,58,59,68,72,73]$. Wang et al. [74] studied 50,000 Medicare beneficiaries for 1-year survival, contrasting baseline comorbidity, prior year comorbidity, change between baseline and prior year comorbidity, 
rolling comorbidity, and change in rolling comorbidity, and found that using all the comorbidity data (and not truncating it by time period) provided the best prediction. Maringe et al. [73] suggested that 6 years of prior administrative data were optimal for validity and reliability.

Types of Visits and Reliability

Using ICD-9 codes from admission, Wang et al. [75] compared all outpatient visits in the antecedent 6 months, all inpatient visits in the antecedent 6 months versus all sources in 3,994 women with breast cancer and found there was poor agreement in diagnoses between specific types of visits.

\section{Concurrent Validity}

Concurrent validity is a clinimetric property that evaluates whether two scales that ostensibly measure or predict the same outcome are significantly correlated or result in concordant predictions. Most studies that evaluated the concurrent validity of the CCI found moderate or greater correlations with other measures that predicted mortality. When comparing the CCI to the Index of Coexistent Disease (ICED) in 1,789 patients with rheumatoid arthritis and osteoarthritis followed over 10 years (with a high mortality rate of 64\%), Gabriel et al. [76] showed that the two measures had a correlation of 0.58 and were independent predictors of mortality. In 7,511 breast cancer patients and 1,482 prostate cancer patients, the CCI had a similar prediction in comparison to a count of the conditions in the CCI [77, 78]. In 347 men with prostate cancer, Alibhai et al. [79] compared the CCI, ICED, disease count, and the number of medications and found that the CCI and the ICED had similar predictors of 6.5-year mortality ( $c=0.61$ for both). Similarly, Albertsen et al. [80] evaluated 451 men with prostate cancer followed over 20 years and found that the CCI, the ICED, and the Kaplan-Feinstein had similar predictions of mortality. In 688 older community dwellers, both CCI and ICED predicted 5-year mortality [81]. In 330 spinal cord injured patients, Rochon et al. [82] compared a count of ICD diagnostic codes and the CCI, and found that both predicted 18-month mortality, yet the Charlson Index outperformed the ICD diagnostic codes. In mitral valve patients undergoing minimally invasive surgery, the CCI and the Society for Thoracic surgeons score were highly correlated; both predicted 1-year mortality [83].

Charlson Comorbidity Index
The diagnostic cost group (DxCG), which was designed to predict cost, and the CCI were compared in 2,167 surgical patients and shown to have a correlation of 0.56 [84]. The American Society of Anesthesiologist classification had a similar but slightly better prediction of 30 -day mortality compared to the CCI in 650,437 patients [85]. Ash et al. [86] predicted 1-year mortality after acute myocardial infraction in 5 different years, each with slightly over 300,000 patients using three different scales: diagnostic cost group with 122 variables with a vector of 118 hierarchies of seriousness, the Agency for HealthCare Research and Quality (AHRQ) clinical classification software (CCS) with 263 variables, and the CCI. Their validation analysis showed a more accurate prediction using the DCG $(c=0.81)$ and the CCS $(c=0.82)$ than the CCI $(c=$ $0.74)[86]$.

In 2,728 Medicare beneficiaries with atrial fibrillation, the Deyo and Romano versions of the CCI were highly correlated (Spearman $=0.8$ ), but much less so with the Elixhauser Index $(r=0.37-0.44)$; the two versions of the CCI had a slightly higher accuracy in predicting mortality [87]. Luchtenborg et al. [88] compared the Charlson and Elixhauser Index in 233,981 patients with lung cancer and found a correlation of 0.82 . In 14,313 HIV patients, the CCI and the Elixhauser Index had similar performance in predicting 1-year mortality, and better performance in predicting 2-year mortality in the validation cohort [89].

\section{Sensitivity}

Clinimetric sensitivity is demonstrated by stepwise increases of mortality with stepwise increases in CCI. In one of the largest studies, Fraccaro et al. [90] evaluated 287,459 adults in Salford UK, and quantified CCI at baseline, 5 years and 10 years, showing that mortality increased stepwise with increasing CCI. Fraccaro et al. [90] also showed than 1 in 10 patients had an increase in CCI over 10 years, from $1.9 \%$ at 1 year, $10.4 \%$ at 5 years, and $15.9 \%$ at 10 years; those who had increases in CCI had a significantly higher mortality at the three specific time points. The larger the increase in CCI, the greater the increase in mortality; in addition, the higher the baseline CCI, the higher the mortality with subsequent increases in CCI over the 10 years [90]. Thus, the more increases in CCI and the more rapid the increases occur, the higher the mortality [90].

There have been similar findings in different populations. In 1,300 acutely hospitalized older adults, 90-day,

Psychother Psychosom 2022;91:8-35 
1-year, and 5-year mortality all increased stepwise with increasing comorbidity [91]. In 385 homeless adults followed over 9 years, controlling for cognitive function, for each 1-point increase in the CCI, the risk of mortality was 9.9\% higher and was consistent across ages [92]. A total of 456,263 newly diagnosed hypertensive patients were followed over 12 years showing significant increases in comorbidity over time; the percent of patients who developed at least one new comorbid condition increased from 36 to $60 \%$ at the end of follow-up [93]. A Danish study enrolled 9,329 breast cancer patients during four different 2-year periods and followed them for 10 years and showed that the CCI predicted overall survival over the 10 years [94]. Over the follow-up period, stepwise increases in CCI predicted a stepwise increase in mortality, although overall survival improved in each of the CCI ranks over the secular intervals [94].

In 1,197 breast cancer patients, compared to women with a Charlson comorbidity score of 0 (no comorbidity), patients with scores of 1,2 , and $3+$ had risk ratios for 10 year mortality of $1.23(p=0.10), 2.58(p<0.001)$, and 3.44 $(p<0.001)$, respectively [95]. In 3,102 patients discharged from the emergency department, over 1-year follow-up mortality increased stepwise from $7.0 \%$ with $0 ; 22 \%$ with $1-2 ; 31 \%$ with $3-4$; and $40 \% \geq 5$ [96]. In a study of 13 geographic regions, patients with lung cancer with a lower Charlson score always had lower 1-year survival than those with a score $>3$ or more, although the magnitude varied across regions [88]. Similarly, in 588 patients with non-small cell lung cancer, with increasing CCI scores there were stepwise decreases in survival at 2, 3, and 5 years [97]. In 533 patients with diabetic nephropathy, Huang et al. [98] showed stepwise increases in mortality over 5 years with increasing CCI score. In 288 incident dialysis patients, the relative risk of death over 1 year increased by 1.54 for each increase of 1 in the CCI [99]. Among 18,179 adults who had been hospitalized in the ICU, Luben et al. [100] showed that the increased comorbidity predicted mortality at 5 and 10 years.

Stepwise increases also occur with in-hospital mortality. One study that involved more than 400,000 patients evaluated CCI in six separate yearly intervals and showed consistent gradients with increased in-hospital mortality as comorbidity increased (both ICD-9 and ICD-10): from $0.3 \%$ with 0 ; to $3 \%$ with $1 ; 5-6 \%$ with 2 ; $9-11 \%$ with 3 ; $13-14 \%$ with $4 ; 15-16 \%$ with 5 , and $21-24 \%$ with $\geq 6$ [19]. D'Hoore et al. [38] showed stepwise increases in mortality in 33,940 adults with ischemic heart disease from $3.1 \%$ inpatient death with $0 ; 10.1 \%$ with $1-2 ; 19.3 \%$ with $3-4$; $32.6 \%$ with $5-6$, and $37.1 \%$ with $\geq 6$. There are similar findings in surgical populations. In 6,188 patients with radical cystectomy, postoperative mortality increased stepwise from $1.7 \%$ with $0 ; 3.0 \%$ with $1 ; 4.2 \%$ with $2 ; 4.3 \%$ with 3 , and $12.1 \%$ with CCI $\geq 4$ [101]. Early mortality also increased stepwise with increasing CCI in 1,062 patients with implantable defibrillators [102]. In addition, summary comorbidity measures work best; it has been shown that a focus on weighted measures of comorbidity, and not individual conditions separately evaluated, provides better prediction than individual conditions [103].

\section{Incremental Validity}

Sechrest [104] originally introduced the clinimetric concept of incremental validity, which refers to the unique contribution or incremental increase in predictive power associated with the inclusion of a particular assessment instrument in the clinical decision process $[7,8,11,104$, 105]. An extremely large number of studies have shown that adding the CCI to the standard clinical assessment significantly increased the predictive value for many different populations and many different clinical outcomes. In 52,187 patients presenting to emergency departments for suspected infection, the CCI in addition to Sequential Organ System Failure Assessment (SOFA) significantly improved the prediction of in-hospital mortality [106]. Similarly, in 6,336 patients who had major surgery, the CCI added significantly to perioperative SOFA scores in predicting 30-day mortality [107]. In 1,202 patients with acute coronary syndrome, the CCI improved the ability of the Global Registry of Acute Coronary Events (GRACE) tool to predict in-hospital mortality [108]; in addition, findings demonstrated that the CCI contributed even more to prediction of mortality after discharge [108]. In a cohort of 201 critically ill patients, comorbidity improved the Acute Physiology and Chronic Health Evaluation (APACHE) prediction of in-hospital mortality [109], while in a larger study with 14,013 ICU patients, the CCI only slightly improved the APACHE predictions [110]. In 469 ICU patients, Christensen et al. [111] found that the CCI along with demographic and key clinical variables predicted in-hospital mortality resulting in similar predictions as physiologic variables. In 959 patients admitted to the ICU in Norway, the CCI significantly improved the ability of the Simplified Acute Physiology Score to predict both 30-day and 1-year mortality [68]. In 675 frail patients with inflammatory bowel disease both the CCI and frailty predicted 11-year mortality [112]. 


\section{Predictive Validity}

The clinimetric property of predictive validity refers to the ability of a rating scale or index to predict clinical outcomes [9]. As Wright and Feinstein [9] noted, this is an important clinimetric property as rating scales and indices "may be used to predict a future outcome or stratify patients into distinctively different prognostic groups." Since the CCI [14] was designed to predict mortality (not disability, major morbidity, quality of life, health care costs, and hospitalization), this analysis focuses first on the CCI's prediction of long-term mortality for which it was designed and then on in-hospital mortality for which it has often been used.

\section{Long-Term Mortality}

We will discuss the contribution of CCI in predicting long-term mortality among hospitalized patients, elderly patients, trauma, surgery and emergency patients, and cancer patients.

\section{Hospitalized Patients}

In 6,602,641 hospitalized adults in France, the CCI predicted 1-year mortality [113]. In 77,440 patients hospitalized in Finland, the CCI predicted mortality over the following 13 years [114]. Among 2,740 older women hospitalized with cardiovascular disease, the CCI predicted 15-year mortality [115]. In 712 patients who had an acute MI, the CCI predicted 18-month mortality [116], while in 29,620 patients hospitalized in Switzerland for acute coronary syndrome, the CCI predicted 1-year mortality as well as in-hospital mortality [117]. Among 32,916 German diabetic patients with incident cardiovascular events, the CCI predicted 1-year mortality [118]. In 533 patients with diabetic nephropathy, the CCI predicted increased 3-year mortality [98].

In 811 patients admitted with $\mathrm{CHF}$, the $\mathrm{CCI}$ predicted 1 -year mortality [119]; similar findings were reported in another study [120] where the CCI predicted 1-year mortality in 897 CHF patients. For 1,808 older patients after hospitalization for acute heart failure, the CCI predicted 1-year survival [72]. In 823 patients with CHF who received implantable defibrillators, the CCI also predicted 5 -year mortality [121]. In 3,120 patients with infective endocarditis, CCI predicted 1-year mortality [122].

Among 4,204 patients hospitalized for their first everchronic obstructive pulmonary disease (COPD) exacerbation, the CCI predicted 1-year mortality as well as inhospital mortality [123]. In 1,023 patients with pulmonary embolism, the CCI predicted 3-year mortality and in-hospital mortality [124]. The CCI also predicted 90day mortality in 41,700 patients with venous thromboembolism [125]. In 2,131 patients with tuberculosis, mortality during treatment was predicted by CCI [126].

In 6,988 patients with ischemic stroke, the CCI predicted 1-year and in-hospital mortality [127], 1-year and 30 -day mortality in another 3,605 patients after acute stroke [128], and 1-year mortality among 1,031 patients with stroke admitted in Denmark [129]. Among 950 patients with ischemic stroke, the CCI predicted increased risk of death significantly over 9 years [130].

In 779 patients with rheumatoid arthritis, the CCI predicted 3-year survival [131]. Among 6,591 patients with rheumatoid arthritis (and 6,591 controls) evaluated over 10 years, the CCI was a significant predictor of all-cause mortality [132]. In 669 patients with systemic lupus followed for 13 years, the CCI was a predictor of long-term survival [133].

In 7,391 incident dialysis patients, the CCI predicted 1 -year survival [134]. In 456 incident dialysis patients, the CCI predicted mortality over follow-up [135], and in 10,759 elderly patients with incident hemodialysis, the CCI was a greater predictor of 10-year survival [136]. In 893 hemodialysis patients, the CCI predicted 6-year mortality which increased as CCI increased [137]. In 2,086 patients on the kidney transplant waiting list, the CCI predicted mortality prior to transplant [138]. In 6,324 kidney transplant recipients, Jassal et al. [139] compared several scales and found that the CCI had the best prediction of 5-year survival, compared to indices specifically designed to predict risk in the end-stage renal disease population. The CCI predicted 1.5-year mortality in 388 patients with chronic kidney disease [140], but several studies suggested that no measure of comorbidity was superior in predicting 1-year survival [141, 142].

\section{Elderly Patients}

In 487,197 older hospitalized adults from New South Wales, the CCI predicted 30-day mortality, and adding frailty did not improve the predictions [143]. A study in 1,313 hospitalized older adults found that the CCI predicted 1 - and 5-year mortality [91]. In 628 older patients who underwent percutaneous coronary interventions, CCI and frailty together improved prediction of 3-year survival [144]. In 93,295 older patients discharged from the emergency department in Denmark, 30-day mortality increased with increasing CCI [145]. Among 4,849 older adults who had trauma, CCI predicted 30 -day mortality [146]. In 2,624 elderly nursing home patients, CCI predicted 6-month mortality [147]. In 50,993 patients 
with dementia, the CCI predicted 1- and 3-year survival [148]. In 1,001 elderly patients dependent on home care, the CCI predicted 1-year survival [149]. In 8,425 geriatric patients with gastrointestinal cancer, the CCI was the most significant predictor of 3-month survival [150].

\section{ICU Patients}

Among 280 ICU patients who survived admission for acute respiratory failure, CCI predicted 1-year mortality [151]. In 959 patients admitted to a general ICU in Norway, the CCI predicted 1-year and 30-day mortality [68]. In 1,049 ICU patients, both the CCI and the APACHE (designed for ICU risk prediction) predicted 6-month mortality [152]. In 1,608 adults admitted to ICU, APACHE predicted mortality but the CCI together with age, sex, and the use of mechanical ventilation had similar predictions as APACHE for 1-year mortality as well as in-hospital mortality [153].

Trauma, Surgery and Emergency Department

Patients

In 129,786 trauma patients, the CCI was the most significant predictor of 30-day mortality [154]. In 3,080 adults who had major trauma, the CCI predicted 1-year mortality [155]. Among 5,621 patients who had myocardial injury after non-cardiac surgery (i.e., increased troponin), those with higher CCI had increased 30-day mortality [156]. In 2,484 patients who had COPD exacerbation who were seen in the emergency department, the CCI predicted 1-year mortality [157].

After emergency abdominal surgery in 390 older adults, the CCI predicted 1-year survival [158]. In another group of 227 elderly surgery patients, increased CCI predicted increased 1-year and 30-day mortality [159]. In 14,522 patients who had transurethral prostate resection (TURP) for benign hyperplasia, CCI predicted 30-day mortality [160], and in 302 patients with TURP the CCI predicted 5-year mortality [161]. The CCI predicted mortality after percutaneous nephrolithotomy in 1,406 patients [162].

In 390 hip fracture patients, the CCI predicted 90-day mortality [163]; in 346 patients with hip fracture, CCI predicted 1-year mortality [164], and in 354 hip fracture patients, CCI predicted 2-year mortality [165]. In 485 older patients with hip fracture, the CCI predicted 30-day mortality [166]. One-year mortality after hip fracture was evaluated in 44,000 patients comparing the 259-item Clinical Classification software from AHRQ and the CCI, and the $\mathrm{c}$ value was 0.71 for Charlson and 0.76 for CCS [167]. In 42,354 patients with total hip replacement after femoral neck fracture, one study found that CCI had only modest predictive power $(c=0.68)$ for 2 - and 5 -year mortality [168]. Among 276,594 patients after total knee replacement or total hip replacement drawn from the Hospital Episodes database in the UK, the study found that the database underreported comorbidity in contrast to primary care records [169]; the authors also found that neither the CCI nor the Elixhauser predicted short-term or 1-year mortality [169]. In 3,480 patients with shoulder arthroplasty, the CCI predicted 90-day mortality [144].

\section{Cancer Patients}

In 8,445 patients with breast cancer, lung cancer, or colorectal cancer, the CCI was found to be the strongest predictor of 5-year survival [170]. In 250,985 patients with small bowel adenocarcinoma and colon cancer, the CCI predicted 5-year survival [171]. The CCI predicted 1 -year survival in 6,964 patients with colorectal cancer surgery [172], 1-year survival of 1,945 patients with resected colon cancer [173], and 1-year survival of 743 patients with re-operation after complications of colorectal surgery [174]. In 11,524 patients with colon cancer, the CCI predicted increased 5-year mortality [175], as well as 5 -year mortality in 308 treated colon cancer patients [176]. In 2,204 patients after colorectal surgery, the CCI predicted 30-day survival [177]. In 1,665 patients with colon cancer and liver cirrhosis, the CCI predicted 5-year survival [178]. In 8,597 patients with anastomotic leak after colon cancer resection, the CCI predicted increased 30-day mortality [179]. In 8,490 patients with pancreatic cancer after surgery, the CCI predicted 90-day mortality [180]. In 1,476 patients with gastric cancer and radical gastrectomy, the CCI predicted 5-year survival [22].

In 14,052 patients with radical prostatectomy followed for more than 7 years, CCI was a significant predictor of mortality [181]. Specifically, the CCI predicted 5-, 10-, and 15-year mortality [181]. In 542 patients after radical prostatectomy, CCI was the most powerful predictor of 6-year survival [182]. In 1,527 men with prostate cancer, the CCI was the most significant predictor of 10 -year mortality [183]. In 345 men with a new diagnosis of prostate cancer, the CCI and ICED had similar predictive accuracy for 6-year survival [79]. In 451 men with localized prostate cancer followed over 20 years, the CCI and the Kaplan-Feinstein were both significant predictors of survival [80]. In 2,425 patients with localized prostate cancer, the CCI predicted survival over an 8 -year median followup [184]. In 1,598 men, CCI was a significant predictor of 10 -year mortality from causes other than prostate cancer [185]. In 5,207 with bladder cancer after cystectomy, CCI
16

Psychother Psychosom 2022;91:8-35 DOI: $10.1159 / 000521288$
Charlson/Carrozzino/Guidi/Patierno 
predicted 90-day survival [186]. The CCI also predicted 4 -year survival after clear cell renal carcinoma [187]. The CCI also predicted 30-day mortality in 5,768 adults who had radical nephrectomy after a diagnosis of renal cell carcinoma [188]. Among 891 patients with bladder cancer, the CCI predicted 5-year mortality [189]. In 1,337 patients who had radical cystectomy, the CCI predicted 5-year survival [190].

In 77,971 breast cancer patients, CCI predicted 1-, 3-, 5-, and 10-year survival [191]. In 1,196 black and white women after breast cancer treatment, the CCI predicted 10 -year survival [95]. In 9,208 patients with radical mastectomy, the CCI predicted 30-day mortality [192].

In 9,579 lung cancer patients, the CCI predicted lung cancer-specific mortality [193]. In several studies, comorbidity predicted 5-year survival in lung cancer [194]. In a total of 9,369 patients with lung cancer treated over 12 years in Denmark, the CCI predicted both 1- and 5-year survival [195]. Another study of 4,500 surgically resected lung cancer patients showed that 3-year survival was predicted by the CCI, but not by the Elixhauser Index [27]. In 233,981 patients with lung cancer from 9 different geographic areas, findings indicated that CCI predicted 1 -year, but not 10-year mortality [88]. Comorbidity predicted 5-year survival in 433 patients with small cell lung cancer [196], and in 426 patients with surgically resected non-small cell lung cancer [197]. A study of 22,073 adults with non-small cell lung cancer showed that the CCI predicted 5-year survival [198]. In another study, 617 patients with small cell and non-small cell lung cancer, the CCI did not predict 3-year mortality [199].

In 50,668 patients with acute myeloid leukemia, the CCI predicted 30-day survival [200]. In 542 patients with multiple myeloma treated with a novel agent, the CCI predicted 1-year mortality [201]. In 2,117 older patients with Hodgkin's lymphoma, the CCI predicted 1-year survival [202]. In 548 patients with laryngeal cancer, the CCI predicted 5-year survival [203].

\section{In-Hospital Mortality}

A variety of systems and severity measures to predict in-hospital mortality are discussed in more detail in Appendix 1 . The CCI was not specifically designed to predict in-hospital mortality, even though it has often been used for this purpose. In 1,501,811 patients with CHF and COPD, the CCI predicted increased in-hospital mortality [204]. In 195,527 patients with atrial arrhythmias, the CCI was an independent predictor of in-hospital mortal- ity [205]. The CCI predicted both in-hospital and 1-year survival in 29,620 patients admitted with acute coronary syndrome to any 1 of 69 Swiss hospitals over a 10-year period [117]. In 529 older cardiac patients, CCI predicted in-hospital death [206]. The CCI predicted in-hospital death after ischemic stroke in elderly patients [207]. In 606 patients with COPD, CCI predicted increased in-hospital mortality [208]. In 535 patients with communityacquired pneumonia, the CCI predicted increased inhospital mortality [209], as well as in 488 older patients with community acquired pneumonia [210]. In 154,378 patients admitted with hyponatremia, the CCI was the most important predictor of in-hospital death [211]. The CCI also predicted in hospital mortality in 3,839 systemic lupus erythematosus (SLE) patients [212], and the ageCCI predicted in-hospital mortality in 847 SLE patients [27]. In 786 patients hospitalized for acute kidney injury, the CCI predicted in-hospital death [213]. In 356,425 patients after non-cardiac surgery, the age-CCI was the best predictor for inpatient mortality [214]. In 5,621 COVID patients [156], and in another study of 2,431 COVID patients [215], the CCI was found to predict in-hospital mortality.

In 5,731 CABG patients older than 80 years, the CCI predicted in-hospital mortality [216]. In 2,837 elderly trauma patients, the CCI predicted in-hospital mortality [217]. In 2,197 cirrhotic patients who had major surgery, the CCI predicted in-hospital mortality [218]. In 6,137,965 patients with hip fracture, in-hospital mortality increased with both CCI and age-CCI $(\mathrm{ROC}=0.767)$ [219]. In 315,464 patients who had surgical resection for digestive cancer, the CCI predicted in-hospital mortality [220].

In 450,414 patients with pancreatic cancer, the CCI predicted in-hospital death [221]. The CCI predicted inhospital mortality in 279 patients after surgery for colorectal carcinoma [21]. In 531 postoperative patients with oral cavity cancer, the CCI predicted in-hospital mortality [222]. In 8,080 dementia patients after hip fracture surgery, the CCI predicted in-hospital mortality especially in the oldest [223].

The predictive validity of the CCI is often compared to systems such as MEDIS groups [224], the Disease Staging system [225], APACHE [226], and the Trauma Injury and Severity Score [227] that were developed to predict in-hospital mortality. Elixhauser created a measure of comorbidity to predict hospital-related events including inhospital mortality, length of stay, and hospital charge from administrative data from 1,779,167 patients hospitalized in California in 1992 [228]. Elixhauser included 30 conditions including acute problems such as blood loss 
and fluid and electrolyte disorders; these conditions were all equally weighted and models with none of the conditions were compared to those with all conditions [228]; predictions increased modestly with an increase in $R^{2}$ from 0.06 to 0.13 for length of stay, and from 0.18 to 0.26 for total charges, but with no significant impact on predicting in-hospital mortality [228].

In 25,503 trauma patients, the CCI predicted in-hospital mortality [229]. In another study with 2,819 trauma patients, CCI did predict in-hospital death, but did not add significantly to trauma and injury severity score (TRISS) estimates [227]. In shoulder arthroplasty patients who had a very low $(0.1 \%)$ risk of death, the Elixhauser was slightly better than the CCI in predicting the risk of death [230].

Quan et al. [43] compared ICD-9 and ICD-10 codes for the CCI and Elixhauser in predicting in-hospital mortality in hospitalized patients in Calgary over a 2-year period and for conditions present at admission; they showed slightly higher $c$ statistics for Elixhauser than CCI for ICD-10 codes (Elixhauser $\mathrm{c}=0.854$ vs. CCI $\mathrm{c}=0.845$ ) [43]. Stukenborg et al. [231] evaluated 211,547 hospitalized patients comparing the Deyo CCI and the Elixhauser Index and found that the latter better predicted in-hospital death than the Deyo CCI. Southern et al. [232] compared the individual conditions in the CCI (without weights) to the individual conditions in the Elixhauser Index to predict in-hospital mortality in 4,833 patients hospitalized in Calgary for acute MI, finding that fluid and electrolyte disorders and other neurological disorders had an odds of 4 or more in predicting mortality, which is not surprising since they reflect inpatient issues; Elixhauser had a higher $\mathrm{c}$ value $(\mathrm{c}=0.793$; 95\% CI 0.768 0.815 ) than the Deyo CCI ( $c=0.704 ; 95 \%$ CI 686-732) [232]. Similar findings were reported in another study: the Elixhauser Index was a better predictor for in-hospital mortality than the CCI in 7,201,900 patients with acute coronary syndrome (Elixhauser $\mathrm{c}=0.837$ vs. CCI $\mathrm{c}=$ 0.822). However, over longer intervals the CCI and Elixhauser equally performed in predicting 30-day mortality among ICU patients ( $c=0.65$ for both) [233].

\section{Re-Weighted "Charlson Comorbidity Indices"}

Some investigators, such as the SEER program by the National Cancer Institute (NCI) Medicare team, used all the CCI codes and weights related to non-cancer comorbidities, thereby preserving the integrity of the CCI and its comparability across applications [234]. Other investigators have modified the original structure of the CCI, keeping some conditions, dropping some and adding other conditions, and re-weighting some or all conditions for their specific study, population, and outcome, often confusingly referring to it as the "Charlson Comorbidity Index." Tables 2 and 3 show the specific conditions and weights of these re-weighted scales, which were selected because they received more than 200 citations; other less frequently cited re-weighted scales are described in Appendix 2.

Quan et al. [235] evaluated 1-year mortality in more than 55,000 patients admitted to hospital, comparing a re-weighted scale named the "Updated Charlson Comorbidity Index" and the CCI, and found a c statistic virtually identical for 1-year mortality (Quan $c=0.896$ vs. Charlson $c=0.894$ ). The Quan "Updated Charlson Comorbidity Index" dropped all cardiovascular disease, except CHF, from the model [235]. Quan et al. [235] also compared the "Quan Updated Charlson" and the CCI in predicting in-hospital mortality in 6,847,599 subjects in 6 countries, again showing extremely small differences in the $\mathrm{c}$ statistic, half favoring the CCI: Switzerland (Quan c $=0.869 ;$ CCI $c=0.876)$; France $($ Quan $c=0.878 ;$ CCI $c=$ 0.882 ); New Zealand (Quan $\mathrm{c}=0.831$; CCI $\mathrm{c}=0.836$ ); Japan (Quan $c=0.727$; CCI $c=0.723$ ); Canada (Quan $c=$ 0.828 ; CCI $c=0.825$ ), and Australia (Quan $c=0.825$; CCI $\mathrm{c}=0.808$ ).

Klabunde et al. [236] evaluated 14,943 patients with breast cancer and 28,868 with prostate cancer through Medicare claims data to develop two new "Charlson" indices (one for breast cancer and one for prostate cancer patients) in order to predict 2-year non-cancer mortality using completely different weightings for each type of cancer, as well as hazard ratios calculated separately for inpatient and physician claims - all validated in a split half sample. There was no comparison to the CCI [236].

Ghali et al. [34] created a new comorbidity index with 7 conditions from the CCI (mainly cardiovascular) to predict in-hospital deaths in 6,326 patients who underwent CABG surgery and validated it in 6,791 patients in 1993. They found that their re-weighted index had only a slightly better performance than the CCI (CCI $c=0.70$ and Ghali $c=0.74)$. Chaudhury et al. [58] developed study-specific weights for 1-year mortality in 7,761 patients admitted to a medical service over 4 years and included age, gender, race, and a diagnosis-related group (DRG) from admission, and the analysis resulted in the incorporation of only 4 of the 17 conditions cited by Deyo. The CCI and the study-specific index had identical prediction for 1-year mortality ( $c=0.73$ for both). No validation study was done [58].
18

Psychother Psychosom 2022;91:8-35 DOI: $10.1159 / 000521288$
Charlson/Carrozzino/Guidi/Patierno 
Table 2. Re-weighted versions of the $\mathrm{CCl}$

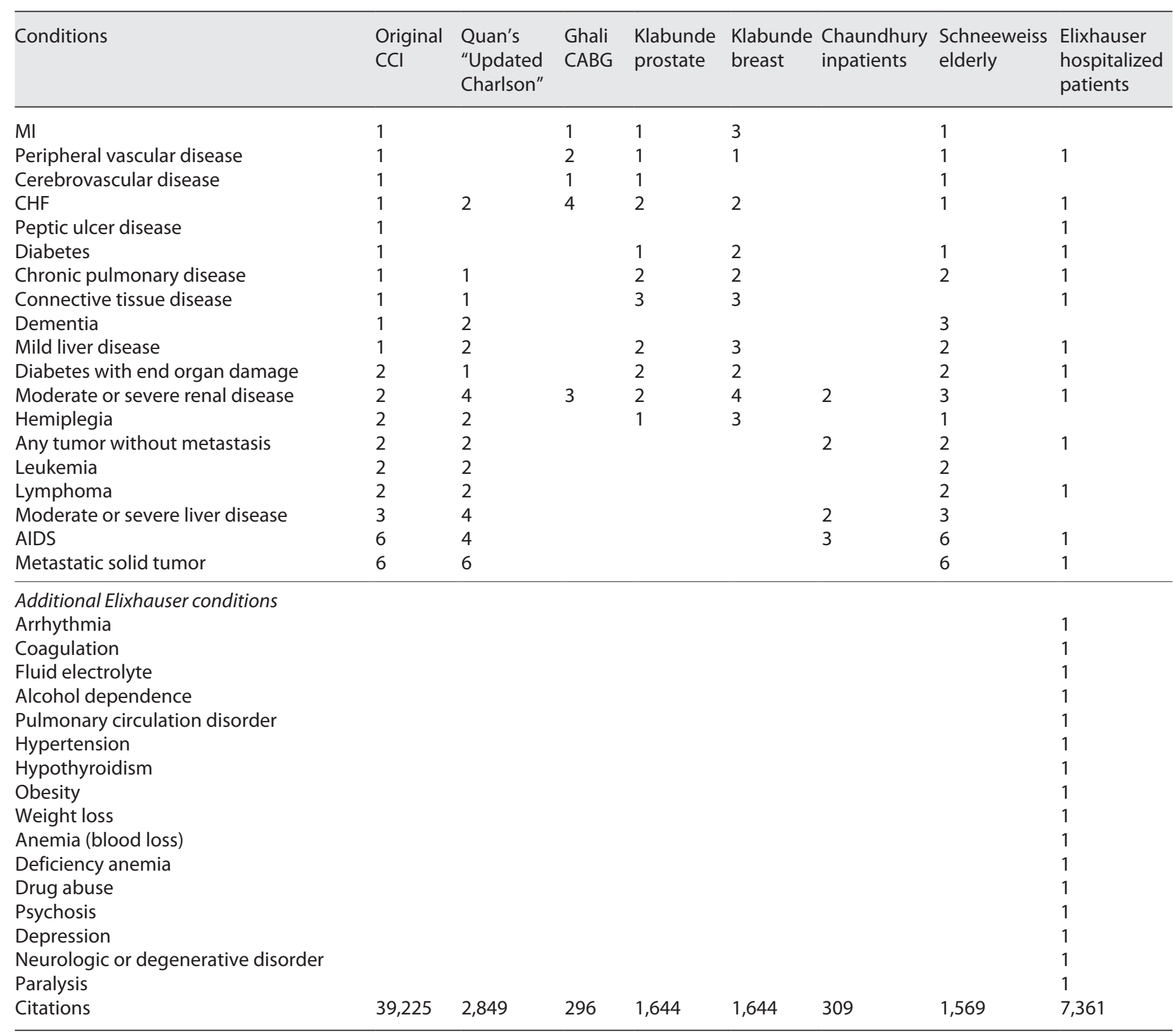

MI, myocardial infarction; CHF, congestive heart failure.

Schneeweiss et al. [40] evaluated several ICD-9 based versions of the CCI (Deyo, Romano, D'Hoore, Ghali) as predictors of 1-year mortality in 141,161 adults aged over 65 years who had received angiotensin-converting enzyme inhibitors or calcium channel blockers in British Columbia and found that the Deyo and Romano versions worked similarly ( $c=0.768$ and $c=0.771$ ), but the Ghali and D'Hoore versions performed less well. The authors pointed out that the Ghali Index performed better in the original CABG study, but Ghali tailored the weights for the CABG populations, leading to loss of predictive utility when applied to different populations [40]. Schneeweiss et al. [237] then evaluated 235,881 Medicare enrollees who had prescription coverage and evaluated the Romano ICD-9-based versions of the CCI versus their new version with elderly-specific weight that re-weighted 10 of the conditions in the index as a predictor of 1-year mortality. They also compared the Chronic Disease Score 
Table 3. The original $\mathrm{CCl}$ and other re-weighted indices

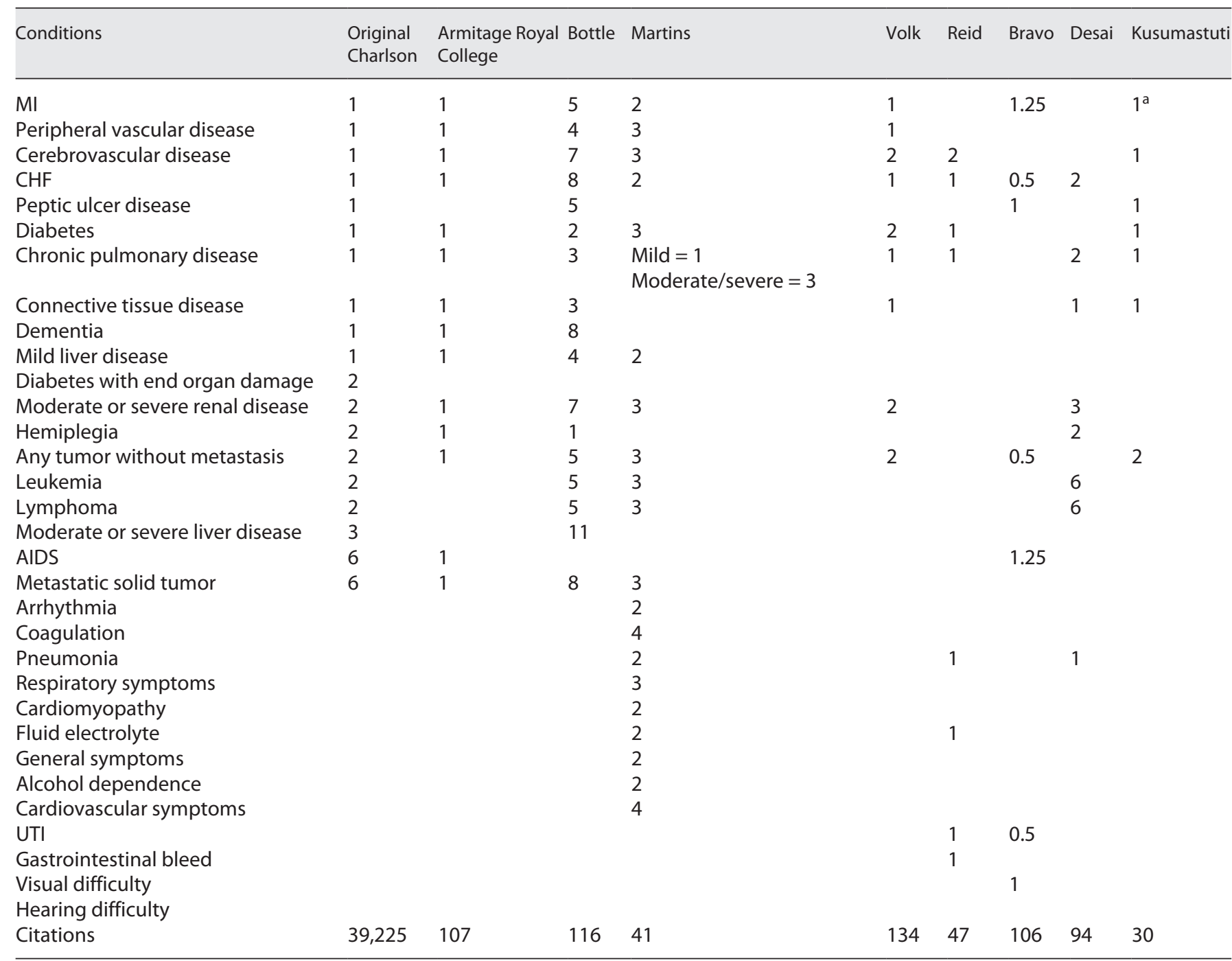

a Includes CHF. MI, myocardial infarction; CHF, congestive heart failure; UTI, urinary tract infection.

[238], the Romano CCI, and their new version in a validation population of 230,913 Medicare patients with pharmacy plans. They found that the Romano version outperformed the Chronic Disease Score and that the Romano CCI version ( $c=0.757 ; 95 \%$ CI $0.754-0.761)$ and their new elderly-specific version $(c=0.765 ; 95 \%$ CI 0.762 0.769 ) were similar in predicting 1-year mortality. They also added the number of distinct prescription drugs given in the baseline year as a predictor and showed minimal improvement in prediction [237]. Other examples of reweighted CCI evaluated on smaller numbers of patients are described in Appendix 2 and Table 3.

A variety of systems, which use a wide range of predictors including chronic conditions to predict outcomes (some of which are called "comorbidity" systems), are discussed in detail in Appendix 3. Appendix 4 describes systems that are primarily designed to predict functional outcomes but are also sometimes referred to as comorbidity systems.

\section{Discussion}

This paper has focused on the clinimetric properties of the original version of the CCI [14], which was designed specifically to predict long-term mortality. The inter-rater reliability of the CCI was found to be excellent, with extremely high agreement between self-report and medi- 
cal charts. There is some underreporting of comorbidity on discharge summaries and claims data, which tend to focus on the conditions leading to hospitalization. The more years of data (i.e., the longer the look-back interval) and the more sources of data (i.e., inpatient and outpatient), the more robust the CCI predictive value.

The CCI has been shown in several studies to either correlate with other indices, such as the ICED, KaplanFeinstein, the DxCG, the American Society of Anesthesiologists (ASA) classification and Elixhauser, or to result in concordant predictions. Clinimetric sensitivity has been demonstrated repeatedly - with a stepwise increase in the CCI, there are stepwise increases in mortality. Importantly, patients who have increased CCI over time have increased mortality rates: the larger the increase in CCI, the larger the increase in mortality. This has been found in adults hospitalized for many reasons, homeless adults, cancer patients, patients discharged from the emergency department, diabetes patients, dialysis patients, and ICU patients after discharge. Similar increases occur with in-hospital mortality: the higher the CCI, the higher the mortality. The incremental validity of the CCI has been shown in different populations; adding the CCI to other measures (i.e., SOFA, GRACE, APACHE) increases the overall predictive accuracy.

From a prognostic viewpoint, findings indicate that the use of the Charlson Comorbidity indices, particularly of the original [239] and revised versions covering the ICD-9 codes [16] and ICD-10 [19], all were accurate predictors of long-term mortality. The predictive validity of the CCI with regard to long-term mortality has been documented in thousands of studies involving millions of patients: hospitalized patients; elderly patients; trauma, surgery, and emergency patients; all types of medical patients, including cancer patients. The CCI also predicts in-hospital mortality in diverse populations such as CHF, arrhythmias, acute coronary syndrome, stroke, COPD, SLE, COVID, cancer, and dementia, as well as patients after CABG, non-cardiac surgery, and hip fractures. However, systems designed to predict mortality in specific circumstances, such as trauma mortality where the TRISS system is focused and the ICU mortality on which APACHE is focused, usually work better for those specific outcomes, but in some instances the CCI adds to the prediction.

From a diagnostic point of view, the evaluation of pretherapeutic comorbidity is a crucial aspect considering that, as emphasized by Feinstein [1], "a co-morbid ailment may produce manifestations that simulate those of the index disease, so that the exact pre-therapeutic state

Charlson Comorbidity Index of the index disease may be difficult to identify." The presence of comorbidity may delay the correct diagnosis and influence treatment decisions [240]. The CCI [14] and one ICD-10 version [19], in view of their clinimetric sensitivity, appear to be clinically useful not only to provide a valid assessment of the patient's unique clinical situation, but also to demarcate major diagnostic and prognostic differences among subgroups of patients who otherwise seem deceptively similar, because they have the same diagnosis [11].

As Feinstein [1, p. 455] noted: "To compare different modes of therapy, clinicians usually assemble groups of patients in whom the results of the treatments are then observed. For the comparison to be scientifically valid, the groups of patients must be initially comparable - they must have enough resemblance, before treatment, for their outcomes to be similar if treatment was not given. Without this pre-therapeutic similarity in the groups of patients, the different treatments cannot be properly evaluated." The evaluation of pre-therapeutic comorbidity is therefore a crucial methodological aspect, which applies not only to research studies (i.e., randomized controlled trials) but also to daily clinical practice to capture the specific comorbid disease combinations affecting the "individual" patient [241].

This review did not focus on "multimorbidity," which has been defined in many different ways, including risk factors for medical conditions [242-245]. Some reviews define the CCI as a measure of multimorbidity $[245,246]$. One definition is two or more illnesses without identifying an index disease [240]. In the majority of studies on multimorbidity, the criteria for the selection of comorbid conditions were not provided, with substantial variability across studies [244]. Further, this review did not focus on other outcomes such as treatment complications, readmissions, length of stay, or cost, none of which were part of the intended outcomes for the comorbidity index.

There are a number of different reviews on the CCI, focusing on ICD-9, ICD-10, and re-weighted versions $[175,247]$. One focused on the clinimetric properties of the CCI [50] and another compared the CCI and Elixhauser [51]. Yurkovich et al. [248] reviewed indices derived from administrative data finding that diagnosisbased indices were better predictors than medicationbased indices of outcomes; the review included two re-weighted CCI scales: Ghali and Quan [248]. Sharabiani et al. [249] reviewed three re-weighted versions of the CCI.

A substantial body of evidence demonstrates that the $\mathrm{CCI}$ is a valid and widely used measure to predict the risk 
of mortality. These clinimetric indices can be applied not only to predict clinical outcomes, but are also highly sensitive screening instruments yielding important diagnostic and prognostic information.

\section{Conclusions}

In clinical research and practice, the time has come to focus on clinimetric indices to provide a timely and comprehensive assessment of comorbidity. The findings of this critical review indicate that the $\mathrm{CCI}$ is a reliable, highly sensitive, and valid index according to current clinimetric criteria [250]. Adding the Charlson Comorbidity Indices to standard diagnostic criteria may provide an innovative assessment approach that can be applied in a variety of medical settings to enable the early identification of a constellation of symptoms and syndromes in the individual patient, to improve the prognostic estimation of health risks, and also to provide a better prediction of clinical outcomes.

\section{Appendix 1}

Systems and Severity Measures Focused on Predicting In-Hospital Mortality

- Systems such as MEDIS Groups assessed 260 key clinical findings at least twice during hospitalization to create groups that assessed risk of organ failure in 54,142 inpatients and showed that in-hospital death rose across the final five groups [224].

- Gonnella et al. [225] took 420 diagnoses, coded them from discharge abstracts by system, etiology, and severity, and used the stages to predict length of hospital stay in 392,456 hospitalized patients. Naessens et al. [251] revised this Disease Staging System into a new scale with 16 body systems that had an increased risk of complications (rated 2 or more by Gonnella et al. [225]) and showed a relation to mortality after hospitalization.

- APACHE, one of the most widely adopted systems for predicting in-hospital death for critically ill ICU patients, was heavily based on 17 acute physiologic values at admission weighted for total scores from 0 to 252 and predicted in-hospital mortality [226, 252].

- Poses et al. [253] used only discharge diagnoses to code the Deyo CCI and compared it to the acute physiologic component of APACHE and to the Chronic Health Points of APACHE. They found that the comorbidity and APACHE predicted death in 201 ICU patients, but not the chronic component of APACHE [253].

- Iezzoni et al. [254] compared MEDIS Groups, APACHE, Gonnella's disease standing as predictors of in-hospital death in 11,880 patients from 100 hospitals in the MEDIS Groups database using data from the discharge abstracts (including such conditions as cardiac arrest, which vastly complicates interpretation); however, those which focused on acute instability in the hospital were better predictors of in-hospital mortality [254].

- The patient management category (PMC) severity scale, a seven-level ordinal scale, is based on the severity rating of 830 patient management categories developed by consensus, each rated from 1 to 4 for severity [255]; it was shown to predict in-hospital mortality in 2.3 million hospitalized patients in two different regions [255].

- The TRISS (Trauma and Injury Severity Score) predicts death after immediate trauma in 2,819 patients and there was no improvement in prediction of trauma-related mortality with the CCI [227].

- The comorbidity index for obstetric patients identified 20 conditions that increased obstetric risk including pre-eclampsia, previous caesarian section, gestational diabetes or hypertension, multiple gestations, and found that it performed better than the CCI in predicting maternal mortality and morbidity (Bateman $\mathrm{c}=$ 0.617 vs. CCI c $=0.578$ ) [256].

- Incalzi et al. [257] evaluated the risk of in-hospital death in 500 geriatric patients and identified 52 conditions which increased risk, both acute (i.e., sepsis) and chronic (i.e., cancer), and showed in a validation cohort of 375 that death was predicted by malnutrition, activities of daily living (ADL), lymphocytopenia, and their own new index.

- van Walraven et al. [258] reweighted the Elixhauser Index using 228,565 patients admitted in Ottawa, assigning weights from -7 to 12 to the remaining 21 conditions, to predict in-hospital mortality. van Walraven et al. [258] compared their version of the Elixhauser to the Scheeweiss weighted version of the CCI [237] and in a validation cohort of 117,230 admitted patients compared the Van Walraven $(c=0.763$; 95\% CI: $0.757-0.769)$ to the Schneewiess ( $c=0.742$; 95\% CI 0.736-0.748) [258].

- Gagne et al. [259] created a "Combined Comorbidity Index" using the 17 conditions from the CCI and the 30 from van Walraven's version of the Elixhauser Index to develop weights from logistic regression coef- 
ficients for 120,679 Medicare subjects enrolled in a pharmacy coverage program and a validation cohort of 123,955 Medicare subjects enrolled in New Jersey. They selected a total of 20 conditions, finding that the c statistic for the Romano CCI for 1-year mortality was $c=0.778$ (95\% CI 0.776-0.780); van Walraven/Elixhauser $(c=0.772,95 \%$ CI $0.770-0.775)$ and their new Combined Comorbidity Index $(c=0.788,95 \%$ CI $0.786-0.781$ ) [259]. There was no validation study.

- Sharma et al. [260] analyzed the Quan ("updated Charlson") Index with 12 conditions compared to the van Walraven-Elixhauser Index versus a newly defined Swiss mode as predictors of in-hospital mortality in 6.09 million adults admitted to Swiss hospitals over a 6-year period, showing that the newly derived model performed best. There are no validation data.

- Overall there are differences in systems that use only discharge data versus those that capture other data [261].

\section{Appendix 2}

\section{Other Examples of Re-Weighted CCI}

Armitage et al. [262] developed a Royal College of Surgeons Charlson Score by translating the CCI into ICD-10 using 3 -digit codes, dropping 2 conditions, and counting up the number of 14 other conditions; the result was an ICD-10 translation that contained far fewer ICD-10 codes than other adaptions to predict in-hospital and 1-year mortality in four separate surgical procedures. It was not compared to any other measures, nor was it validated in a separate population [262].

Bottle and Aylin [263] re-weighted the ICD-10 CCI for 5.4 million patients in the UK, sourcing the index by calculating the regression coefficient for each of the conditions and dividing it by the smallest regression coefficient in the model, creating four new weighted indices using the Charlson conditions, assigning four separate weights for all conditions (i.e., severe liver disease was weighted 11 in one model; 9 in another; 27 in another, and 5 in another) and found a small difference in mortality rate (CCI $c=0.719$ and Bottle $c=0.726$ ) for predicting in-hospital mortality [263]. These findings were not validated in a separate population.

Bravo et al. [264] created a new weighted comorbidity index to predict mortality after 3 years among 291 longterm care patients, by re-weighting 5 conditions and adding 2 more conditions, and showed the diseases specific predictive accuracy $(c=0.86)$ versus the CCI $(c=0.79)$.
This long-term care mortality index was not validated in a separate population.

Desai et al. [265] developed another scale focused on conditions identified as high risk for elderly patients in 524 patients. Their resultant High Risk in Elderly Scale was validated in a population of 852 and had a c statistic for 1-year mortality of 0.69 versus 0.65 for the Deyo/ Charlson [265]. The Cox model showed identical relative risks $(1.9,95 \%$ CI 1.5-2.1) [265]. There is no separate validation.

Kusumastuti et al. [266] focused on 36,751 community-dwelling elderly using 7 re-weighted conditions in the $\mathrm{CCI}$, predicting 1 - and 3-year mortality in relation to frailty and frailty phenotype, and showed limited added value of their new estimate of comorbidity in predicting 1- and 3-year mortality. These findings were not evaluated in a separate population.

Reid et al. [267] created a disease-specific comorbidity index in 9,386 head and neck cancer patients (with 4 conditions from the CCI and conditions which were complications, like pneumonia, urinary tract infection, and electrolyte imbalance) in predicting 5-year mortality and found that the CCI and their new head and neck index had almost identical relative risks for survival: 1.5 and 1.53 , respectively. The disease-specific index was not validated in a separate population.

Volk et al. [268] developed a "modified Charlson" index to predict 4-year mortality in 624 patients after liver transplant using 9 re-weighted conditions and showed increased mortality with one or more conditions from the "modified" index; this was not validated in a separate population.

Martins et al. [269] developed a new study-specific index to predict in-hospital death among 54,680 patients admitted over a 2-year period for respiratory illnesses, with 8 of the original 19 conditions re-weighted and added to another 13 conditions including symptoms to predict in-hospital death. It was validated in a separate population of 14,622 patients with respiratory illnesses (CCI original; $\mathrm{c}=0.721 ; 95 \%$ CI $0.701-0.740)$ versus Martins (c = 0.755, 95\% CI 0.730-0.774) [269].

Baldwin et al. [270] tested a colon cancer-specific Klabunde Index (no published weights) versus the Elixhauser to predict 2-year non-cancer mortality in colon cancer patients and found that neither measure was a better predictor of short-term mortality; there was no validation in a separate population.

Toson et al. [271] conducted a study of hip fracture patients that compared the CI [19] vs. Quan Charlson [235] and showed puzzling differences in the rates of de- 
mentia (4 times higher with Quan): it was found that the CCI outperformed Quan for in-hospital mortality ( $c=$ 0.734 vs. 0.720 ) and Quan did slightly better for 1-year mortality ( 0.071 vs. 0.690$)$ [271]. There is no separate validation.

\section{Appendix 3}

Other Systems That Have Been Set Up to Evaluate Comorbidity to Predict Survival

Most are called comorbidity indices, and many do not have validation populations [2].

- Cardiac arrest: Hallstrom et al. [272] created a comorbidity assessment to predict survival after out-of-hospital ventricular fibrillation using 10 chronic conditions and 6 recent symptoms that occurred in 282 patients pre-cardiac arrest. There was no validation (111 citations).

- Community dwelling elderly: Cornoni-Huntley [273, 274] created a comorbidity assessment from five specific conditions: coronary artery disease, cerebrovascular disease, cancer, hypertension, and diabetes, and the presence of two or more of the conditions as predictors of 6-year mortality in 4,126 community dwelling elderly. There was no validation (9236 citations).

- Breast cancer: Satariano et al. [275] totaled the number of seven specific conditions (i.e., "comorbidity" such as diabetes, gallbladder disease, cancer) to estimate the impact on 3-year survival in 963 women with breast cancer. There was no validation (823 citations).

- Dialysis/transplant: Khan et al. [276] developed a 3-level scale focused on 6 specific chronic conditions (i.e., diabetes, cancer, COPD) to predict 2-year survival in 375 dialysis or transplant patients. There was no validation (320 citations).

- End-stage renal disease: Davies et al. [277] picked seven disease areas (i.e., rheumatic disease, left ventricular dysfunction) in a three-level scale to predict 5-year survival in 303 peritoneal dialysis patients. There was no validation (403 citations).

- End-stage renal disease: van Manen et al. [278] showed that the Deyo version was a better predictor of 2-year survival in end-stage renal disease patients than Davies or Khan; van Manen et al. [278] created their own disease-specific index, which was comprised of the $\beta$-coefficients for diseases that predicted 2-year survival in their cohort; their index had a $c$ value of 0.75 like Deyo $(c=0.74)$ [278] (212 citations).
- Dialysis: Liu et al. [279] tested their new comorbidity dialysis-specific index in 244,651 patients with four conditions related to renal disease and 11 other conditions all weighted to predict 3-year survival; they found that the performance in the validation study was virtually identical to the CCI (dialysis index $\mathrm{c}=0.6698$; CCI $c=0.6623$ ) [279] (275 citations).

- Adults: Rius et al. [280] selected 16 conditions (i.e., cataract, skin conditions, allergy, diabetes) weighted them on a four-point scale differently for 6,641 men and women over 40 years old in Catalonia to predict 5 -year survival in 6,600 adults. There was no validation (53 citations).

- Lung cancer: Colinet et al. [281] created a 6 item weighted measure from an initial group of 735 with non-small cell cancer (i.e., tobacco $=7$; diabetes $=5$; and cancer $=1$ ) and validated it as a predictor of 1 -year survival in 136 patients with non-small cell cancer (190 citations).

- Hospitalized patients: Sessler et al. [282] created a Risk Stratification Index, which used between 184 and 1,096 of the 16,000 ICD-9 diagnoses and 4,500 ICD-9 procedure codes to predict in-hospital mortality, 1 -year mortality, and length of stay. They evaluated 35,179,507 Medicare provider analysis and review (MEDPAR) patient stay records split into a development and a validation data set, and developed tables to calculate the risks for each of the outcomes for specific individuals in studies [282]. The new index had "almost perfect" prediction of in-hospital mortality ( $c=0.98)$ than the CCI ( $c=0.65$; which is not surprising), since it was calculated from discharge diagnoses. With 1-year mortality, the new index had a slightly better $\mathrm{c}$ statistic $(c=0.83)$ than the CCI $(c=0.77)[282]$ (105 citations).

- Holman et al. [283] developed the Multipurpose Australian Comorbidity Scoring System using 102 conditions from ICD-9 (i.e., gout and cataract) that were associated with an increased risk of 1-year mortality in $1,118,989$ patients admitted for medical, procedural, or psychiatric reasons. They then tested it in five smaller groups of patients from the same cohort admitted for either asthma, MI, mastectomy, TURP, or psychiatric reasons. The $\mathrm{c}$ statistics for CCI versus their scoring system were quite similar for 1-year mortality in the five groups (e.g., asthma, $c=0.88 \mathrm{CCI}$ and MACSS, $c=0.9$ ) [283] but the multipurpose Australian comorbidity scoring system (MACSS) did better in predicting length of stay and 30-day re-admission rates (130 citations). 
- Older adults: Newman et al. [284] created a Physiologic Index of Comorbidity from carotid ultrasound, pulmonary function tests, brain magnetic resonance scans, serum cystatin-c and fasting glucose to predict 9 -year mortality in 2,928 subjects enrolled in the Cardiovascular Health Study. However, the physiological index predicted mortality only slightly more than age, race, and gender $(c=0.726)$ than the physiological in$\operatorname{dex}(c=0.735)$. There was no validation (120 citations).

- Veterans: among primary care patients at Veterans Affairs centers, the Seattle Index of Comorbidity was developed to predict 2 -year mortality from 24 conditions in 5,469 patients resulting in a scale containing age, six chronic conditions (cancer, $\mathrm{CHF}$, diabetes, stroke, lung disease, and prior MI), one acute condition (pneumonia), and 2 variables for smoking (past and current) [285]. Validated in 5,478 patients, it predicted 2 -year mortality with an explanatory power identical to the PCS and MCS in the SF-36 [285] (173 citations).

- In 1,741 Australian veterans Byles et al. [286] tested an index of 25 conditions, including hearing problems, cancer, and "fits, faints, and funny turns," rated by the patients according to severity (from 1 to 7 ) and then developed independently weighted scales to predict mortality and hospital admission from the derivation data $(n=869)$. They found that the scales did not predict both mortality and admission in the validation data set $(n=434)$, with and without adjustment for baseline quality of life (119 citations).

- Residents of Ontario, Canada: Austin et al. [287] calculated Adjusted Clinical Groups (ACGs) after all ICD-9 or ICD-10 codes that were clustered into 32 aggregated diagnostics groups (ADG), based on each specific condition's severity, duration, etiology, need for specialty care and diagnostic certainty. Each person may have between 0 and 32 ADGs. The 32 ADGs are collapsed into 12 Collapsed ADGs, and then into 102 ACGs, which have patients with similar resources consumption. A total of 10,498,413 adults in Ontario were divided into a derivation and validation data set to predict 1-year mortality [287]. The final ADG model had a c statistic for 1 year of 0.917 compared to 0.906 for Charlson in the validation cohort [287] (261 citations).

- Diabetes: Austin et al. [288] had similar findings with incident and prevalent diabetes showing that in $1,226,146$ patients the ADG had a slightly higher $\mathrm{c}$ statistic (i.e., $\mathrm{ADG} c=0.838$ vs. $\mathrm{CCI} c=0.827$ ) in the validation sample in the larger prevalent population (21 citations).
- Rheumatic disease: England et al. [289] evaluated an index designed to predict functional outcomes and 1 -year mortality specifically developed in 4,765 patients with rheumatic disease consisting of 8 conditions all given a weight of two. There was no validation (139 citations).

- Australian women: In 5,217 older Australian women, Tooth et al. [290] identified 7 out of 19 separate conditions, including heart disease, stroke, and low iron, each with their own weights to develop thirteen separate scales to predict mortality, physician visits, specialty visits, hospitalizations, ADL, and each of the 8 individual SF-36 subscales. They found that none of the scales predicted all of the outcomes, but their 7 conditions predicted mortality [290]. There was no validation (106 citations).

- Prostate cancer: Fleming et al. [291] developed a new comorbidity index in 2,931 black men with prostate cancer to predict 5-year all-cause mortality using 20 conditions and their two-, three-, and four-way interactions. They selected the model with two-way interactions but had limited clarity and performance in predicting outcomes [291]. There was no validation (31 citations).

- Hematopoietic cell transplant: another new comorbidity index was created for 1,055 allogeneic hematopoietic cell transplant patients, divided into a training and validation data set, using laboratory abnormalities, 8 new conditions, and re-weighted and combined 10 of the conditions in the CCI to predict 4-year survival [292, 293]; this index showed a higher $c$ value than the CCI $[292,293]$. Others created a comorbidity index for such transplants from ferritin, albumin, and platelet counts [294] (2,241 citations).

Medication-based indices

- Von Korff et al. $[238,295]$ developed a Chronic Disease Scale from 27 different weighted classes of pharmaceuticals and validated it for its ability to predict 1 -year mortality in a separate population of 122,911 adults in Group Health (654 citations).

- George et al. [296] developed a Medication-Based Disease Burden Index from a consensus panel-weighted list of multiple different medications used to treat 20 chronic diseases enrolled in a randomized clinical trial of community pharmacy service to predict death or readmission which occurred in $24 \%$ of 317 patients within 12 weeks. There was not a validation study. Prediction was greater than the Chronic Disease Score, but not as good as the CCI [296] (57 citations). 


\section{Appendix 4}

Systems Described as Systems to Classify Comorbidity That Focused Primarily on Predicting Functional Outcomes

These systems were developed from assessing body systems (i.e., neurologic, cardiovascular) or the presence of specific diagnoses/conditions to predict functional outcomes, but are sometime referred to as comorbidity measures.

- To estimate the degree of physical impairment, Linn et al. [297, 298] developed the Cumulative Illness Rating Scale, which assessed 13 organ systems, weighted 0-4 for severity. However, the Cumulative Illness Rating Scale did not correlate with ADL, Independent Activities of Daily Living (IADL), or European Cooperative Oncology Group physical function in 203 geriatric patients [299], nor with functional disability in 439 geriatric institutionalized residents [300].

- The burden of disease, based on the symptoms, complications, treatment complexity, procedures, hospitalizations, and emergency room visits, assessed by reviewers to ascertain the presence and severity of 59 chronic or acute medical conditions in 194 long-stay nursing home patients showed a low but significant correlation with ADL $(r=0.21)$ to predict independent activities of daily living and no relation with perceived health status [301].

- Liu et al. [302] developed a "comorbidity" measure in 106 stroke patients admitted for in-hospital rehabilitation, which rated 130 conditions (including eczema and gallstones) from 0 to 5 based on the need for rehabilitation, and found it predicted functional impairment, as did the CCI. It was later revised in 175 stroke patients to 41 conditions leading to a 6-point scale reflecting limitations in activity and shown to predict functional impairment [303].

- Groll et al. [304] developed a Functional Comorbidity Index with 7 of the conditions in the Charlson Index and 11 other conditions to predict 1-year physical function in 73 acute respiratory distress survivors and showed it predicted SF-36 physical function. Another study found that neither the Functional Comorbidity Index nor Charlson were predictors of functional status at the time of admission to acute rehabilitation for 105,441 Medicare patients who had either a stroke, joint replacement, or lower extremity fracture [202]. Another study had a similar finding that CCI did not predict SF-36 PCS scores 1 year after total joint replacement [305].
- Tessier et al. [306] evaluated Groll's Functional Comorbidity Index, the CCI, and their own stroke-specific index to predict functional recovery using a new measure that combined IADL and SF-36 physical function outcomes of stroke in 437 patients after discharge and 235 patients at 3 months, and found that the CCI had a c statistic of 0.763 at discharge and 0.714 after 3 months greater or equal to the other measures.

- The ICED focused on ratings of severity of 14 categories of co-existent conditions, and the degree of physical impairment that were combined into a four-tier scale which was a significant predictor of 1-year functional outcomes (i.e., IADL) [307]. The reliability of the index was moderate because agreement on rating disease severity was low $(\kappa=0.4)$ because the agreement on the functional severity component was higher than the disease severity component [308]. The ICED predicted the health status in 55 patients with angina [309]. The ICED was used in several studies to predict 1-year mortality in dialysis patients [142] and long-term mortality in prostate cancer patients [80].

- The Duke Severity of Illness checklist records each of 803 outpatient diagnoses (from sprains to heart disease) and rates them by symptoms and complications in the last week, treatability, and 6-month prognosis [310]. Severity of illness was related negatively to physical and emotional function [311].

- The Geriatric Index of Comorbidity took the 15 conditions in the ICED and weighted them 0-4 for severity, and then re-grouped them into a 4-rank scale that was associated with disability [312]. The Geriatric Index of Comorbidity showed that by 1 year after hospital discharge, of 444 elderly, $31 \%$ were institutionalized and $22 \%$ had died. The Geriatric scale was divided into classes and compared to quartiles of other measures with $p$ values calculated for each rank-complicating interpretation [313].

- Crabtree et al. [314] developed a comorbidity symptom scale in 50 ophthalmologic patients selecting 23 symptoms that might arise from chronic conditions (i.e., cough, urinary problems), each coded $0-5$ for severity and tested it in 183 patients aged over 65 years and found a correlation of 0.54 with activities of daily living.

- In 157 Health Maintenance Organization (HMO) members, Bayliss et al. [315] assessed 25 conditions identified from the literature, weighted from 1 to 5 according to the patient's assessment of the extent to which each condition interfered with their daily activities. They showed that the estimates of how all conditions interfered with function correlated with health status and physical function as measured by the SF-36 [315]. 
- Verbrugge et al. [316] evaluated how the total number of chronic conditions, 13 specific conditions, and 88 pairs of conditions impacted physical disability as assessed by ADL and IADL, and found the more conditions the more disability.

\section{Conflict of Interest Statement}

M.E.C.reportsthefollowinggrants:PCORI(IHS-2017C3-8923), NHLBI (T32 HL135465-01A), and NIMHD (5T37MD014220-02) outside of the submitted work, and Cornell University has filed a patent for the use of the enhanced comorbidity index to predict future costs. All other authors have no conflicts of interest to declare.

\section{Funding Sources}

There are no funding sources to declare.

\section{Author Contributions}

All the authors conceived the work. M.E.C., D.C., J.G., and C.P. searched, screened, and selected studies. All the authors drafted and finalized the paper.

\section{References}

1 Feinstein AR. The pre-therapeutic classification of co-morbidity in chronic disease. J Chronic Dis. 1970 Dec;23(7):455-68.

2 de Groot V, Beckerman H, Lankhorst GJ, Bouter LM. How to measure comorbidity: a critical review of available methods. J Clin Epidemiol. 2003 Mar;56(3):221-9.

3 Fava GA, Tossani E, Bech P, Berrocal C, Chouinard G, Csillag C, et al. Emerging clinical trends and perspectives on comorbid patterns of mental disorders in research. Int J Methods Psychiatr Res. 2014 Jan;23(Suppl 1):92-101.

4 Kessler RC, Chiu WT, Demler O, Merikangas KR, Walters EE. Prevalence, severity, and comorbidity of 12-month DSM-IV disorders in the National Comorbidity Survey Replication. Arch Gen Psychiatry. 2005 Jun;62(6): 617-27.

5 Bech P. Modern psychometrics in clinimetrics: impact on clinical trials of antidepressants. Psychother Psychosom. 2004 May-Jun; 73(3):134-8.

6 Fava GA, Carrozzino D, Lindberg L, Tomba E. The clinimetric approach to psychological assessment: a tribute to Per Bech, MD. Psychother Psychosom. 2018 Nov;87(6):321-6.

7 Carrozzino D, Patierno C, Fava GA, Guidi J. The Hamilton rating scales for depression: a critical review of clinimetric properties of different versions. Psychother Psychosom. 2020 May;89(3):133-50.

8 Fava GA, Rafanelli C, Tomba E. The clinical process in psychiatry: a clinimetric approach. J Clin Psychiatry. 2012 Feb;73(2):177-84.

9 Wright JG, Feinstein AR. A comparative contrast of clinimetric and psychometric methods for constructing indexes and rating scales. J Clin Epidemiol. 1992 Nov;45(11):1201-18.

10 Feinstein AR. Clinimetrics. New Haven: Yale University Press; 1987.

11 Fava GA, Tomba E, Sonino N. Clinimetrics: the science of clinical measurements. Int $J$ Clin Pract. 2012 Jan;66(1):11-5.
12 Gijsen R, Hoeymans N, Schellevis FG, Ruwaard D, Satariano WA, van den Bos GA. Causes and consequences of comorbidity: a review. J Clin Epidemiol. 2001 Jul;54(7):66174.

13 Kaplan MH, Feinstein AR. The importance of classifying initial co-morbidity in evaluating the outcome of diabetes mellitus. J Chronic Dis. 1974 Sep;27(7-8):387-404.

14 Charlson ME, Pompei P, Ales KL, MacKenzie CR. A new method of classifying prognostic comorbidity in longitudinal studies: development and validation. J Chronic Dis. 1987 Jan; 40(5):373-83.

15 Charlson ME, Szatrowski TP, Peterson J, Gold J. Validation of a combined comorbidity index. J Clin Epidemiol. 1994 Nov;47(11): 1245-51.

16 Deyo RA, Cherkin DC, Ciol MA. Adapting a clinical comorbidity index for use with ICD9-CM administrative databases. J Clin Epidemiol. 1992 Jun;45(6):613-9.

17 Katz JN, Chang LC, Sangha O, Fossel AH, Bates DW. Can comorbidity be measured by questionnaire rather than medical record review? Med Care. 1996 Jan;34(1):73-84.

18 Romano PS, Roos LL, Jollis JG. Adapting a clinical comorbidity index for use with ICD9-CM administrative data: differing perspectives. J Clin Epidemiol. 1993 Oct;46(10): 1075-9.

19 Sundararajan V, Henderson T, Perry C, Muggivan A, Quan H, Ghali WA. New ICD-10 version of the Charlson comorbidity index predicted in-hospital mortality. J Clin Epidemiol. 2004 Dec;57(12):1288-94.

20 Wu CC, Hsu TW, Chang CM, Yu CH, Lee CC. Age-adjusted Charlson comorbidity index scores as predictor of survival in colorectal cancer patients who underwent surgical resection and chemoradiation. Medicine. 2015 Jan;94(2):e431.
21 Ouellette JR, Small DG, Termuhlen PM. Evaluation of Charlson-age comorbidity index as predictor of morbidity and mortality in patients with colorectal carcinoma. J Gastrointest Surg. 2004 Dec;8(8):1061-7.

22 Lin JX, Huang YQ, Xie JW, Wang JB, Lu J, Chen QY, et al. Association of the age-adjusted Charlson Comorbidity Index and systemic inflammation with survival in gastric cancer patients after radical gastrectomy. Eur J Surg Oncol. 2019 Dec;45(12):2465-72.

23 Asano T, Yamada S, Fuji T, Yabusaki N, Nakayama G, Sugimoto $H$, et al. The Charlson age comorbidity index predicts prognosis in patients with resected pancreatic cancer. Int J Surg. 2017 Mar;39:169-75.

24 Daskivich TJ, Kwan L, Dash A, Saigal C, Litwin MS. An age adjusted comorbidity index to predict long-term, other cause mortality in men with prostate cancer. J Urol. 2015 Jul; 194(1):73-8.

25 Kahl A, du Bois A, Harter P, Prader S, Schneider S, Heitz F, et al. Prognostic value of the age-adjusted Charlson Comorbidity Index (ACCI) on short- and long-term outcome in patients with advanced primary epithelial ovarian cancer. Ann Surg Oncol. 2017 Nov; 24(12):3692-9.

26 Suidan RS, Leitao MM, Zivanovic O, Gardner GJ, Long Roche KC, Sonoda Y, et al. Predictive value of the age-adjusted Charlson Comorbidity Index on perioperative complications and survival in patients undergoing primary debulking surgery for advanced epithelial ovarian cancer. Gynecol Oncol. 2015 Aug;138(2):246-51.

27 Yang CC, Fong Y, Lin LC, Que J, Ting WC, Chang CL, et al. The age-adjusted Charlson comorbidity index is a better predictor of survival in operated lung cancer patients than the Charlson and Elixhauser comorbidity indices. Eur J Cardiothorac Surg. 2018 Jan;53(1): $235-40$. 
28 Kang HW, Kim SM, Kim WT, Yun SJ, Lee SC, Kim WJ, et al. The age-adjusted Charlson Comorbidity Index as a predictor of overall survival of surgically treated non-metastatic clear cell renal cell carcinoma. J Cancer Res Clin Oncol. 2020 Jan;146(1):187-96.

29 Elshaikh MA, Vance S, Kamal M, Burmeister C, Hanna RK, Rasool N, et al. Influence of comorbidity on the risk of death: a single institution study of 1132 women with early-stage uterine cancer. Am J Clin Oncol. 2017 Apr; 40(2):183-8.

30 Jiang L, Chou ACC, Nadkarni N, Ng CEQ, Chong YS, Howe TS, et al. Charlson Comorbidity Index predicts 5-year survivorship of surgically treated hip fracture patients. Geriatr Orthop Surg Rehabil. 2018 Nov;9: 2151459318806442.

31 Schmolders J, Friedrich MJ, Michel R, Strauss AC, Wimmer MD, Randau TM, et al. Validation of the Charlson Comorbidity Index in patients undergoing revision total hip arthroplasty. Int Orthop. 2015 Sep;39(9):1771-7.

32 Di Iorio B, Cillo N, Cirillo M, De Santo NG. Charlson Comorbidity Index is a predictor of outcomes in incident hemodialysis patients and correlates with phase angle and hospitalization. Int J Artif Organs. 2004 Apr;27(4): $330-6$.

33 St-Louis E, Iqbal S, Feldman LS, Sudarshan M, Deckelbaum DL, Razek TS, et al. Using the age-adjusted Charlson Comorbidity Index to predict outcomes in emergency general surgery. J Trauma Acute Care Surg. 2015 Feb; 78(2):318-23.

34 Ghali WA, Hall RE, Rosen AK, Ash AS, Moskowitz MA. Searching for an improved clinical comorbidity index for use with ICD-9-CM administrative data. J Clin Epidemiol. 1996 Mar;49(3):273-8.

35 Cleves MA, Sanchez N, Draheim M. Evaluation of two competing methods for calculating Charlson's comorbidity index when analyzing short-term mortality using administrative data. J Clin Epidemiol. 1997 Aug;50(8):903-8.

36 Roos LL, Stranc L, James RC, Li J. Complications, comorbidities, and mortality: improving classification and prediction. Health Serv Res. 1997 Jun;32(2):229-38.

37 Khan NF, Perera R, Harper S, Rose PW. Adaptation and validation of the Charlson index for read/OXMIS coded databases. BMC Fam Pract. 2010 Jan;11:1.

38 D'Hoore W, Bouckaert A, Tilquin C. Practical considerations on the use of the Charlson Comorbidity Index with administrative data bases. J Clin Epidemiol. 1996 Dec;49(12): 1429-33.

39 D'Hoore W, Sicotte C, Tilquin C. Risk adjustment in outcome assessment: the Charlson Comorbidity Index. Methods Inf Med. 1993 Nov;32(5):382-7.

40 Schneeweiss S, Seeger JD, Maclure M, Wang PS, Avorn J, Glynn RJ. Performance of comorbidity scores to control for confounding in epidemiologic studies using claims data. Am J Epidemiol. 2001 Nov;154(9):854-64.
41 Hosmer DW, Lemeshow S. Applied logistic regression. 2nd ed. New York: John Wiley; 2000.

42 Halfon P, Eggli Y, van Melle G, Chevalier J, Wasserfallen JB, Burnand B. Measuring potentially avoidable hospital readmissions. J Clin Epidemiol. 2002 Jun;55(6):573-87.

43 Quan H, Sundararajan V, Halfon P, Fong A, Burnand B, Luthi JC, et al. Coding algorithms for defining comorbidities in ICD-9-CM and ICD-10 administrative data. Med Care. 2005 Nov;43(11):1130-9.

44 World Health Organization (WHO). International classification of diseases twoway translator for the ninth and tenth revisions. Geneva: World Health Organization; 1997.

45 Nuttall M, van der Meulen J, Emberton M. Charlson scores based on ICD-10 administrative data were valid in assessing comorbidity in patients undergoing urological cancer surgery. J Clin Epidemiol. 2006 Mar;59(3):26573.

46 Sundararajan V, Quan H, Halfon P, Fushimi $\mathrm{K}$, Luthi JC, Burnand B, etal . Cross-national comparative performance of three versions of the ICD-10 Charlson index. Med Care. 2007 Dec;45(12):1210-5.

47 Hall SF, Groome PA, Streiner DL, Rochon PA. Interrater reliability of measurements of comorbid illness should be reported. J Clin Epidemiol. 2006 Sep;59(9):926-33.

48 Waite K, Oddone E, Weinberger M, Samsa G, Foy M, Henderson W. Lack of association between patients' measured burden of disease and risk for hospital readmission. J Clin Epidemiol. 1994 Nov;47(11):1229-36.

49 Bernardini J, Callen S, Fried L, Piraino B. Inter-rater reliability and annual rescoring of the Charlson comorbidity index. Adv Perit Dial. 2004;20:125-7.

50 Roffman CE, Buchanan J, Allison GT. Charlson comorbidities index. J Physiother. 2016 Jul;62(3): 171

51 Molto A, Dougados M. Comorbidity indices. Clin Exp Rheumatol. 2014 Sep-Oct;32(5 Suppl 85):S131-4.

52 Olomu AB, Corser WD, Stommel M, Xie Y, Holmes-Rovner M. Do self-report and medical record comorbidity data predict longitudinal functional capacity and quality of life health outcomes similarly? BMC Health Serv Res. 2012 Nov; 12:398.

$53 \mathrm{Ng}$ X, Low AHL, Thumboo J. Comparison of the Charlson comorbidity index derived from self-report and medical record review in Asian patients with rheumatic diseases. Rheumatol Int. 2015 Dec;35(12):2005-11.

54 Levy AR, Tamblyn RM, Fitchett D, McLeod PJ, Hanley JA. Coding accuracy of hospital discharge data for elderly survivors of myocardial infarction. Can J Cardiol. 1999 Nov; 15(11):1277-82.

55 Shwartz M, Iezzoni LI, Moskowitz MA, Ash AS, Sawitz E. The importance of comorbidities in explaining differences in patient costs. Med Care. 1996 Aug;34(8):767-82.
56 Lichtensztajn DY, Giddings BM, Morris CR, Parikh-Patel A, Kizer KW. Comorbidity index in central cancer registries: the value of hospital discharge data. Clin Epidemiol. 2017 Nov;9:601-9.

57 Daskivich TJ, Abedi G, Kaplan SH, Skarecky D, Ahlering T, Spiegel B, et al. Electronic health record problem lists: accurate enough for risk adjustment? Am J Manag Care. 2018 Jan;24(1):e24-9.

58 Chaudhry S, Jin L, Meltzer D. Use of a selfreport-generated Charlson comorbidity index for predicting mortality. Med Care. 2005 Jun;43(6):607-15.

59 Zhang JX, Iwashyna TJ, Christakis NA. The performance of different lookback periods and sources of information for Charlson comorbidity adjustment in medicare claims. Med Care. 1999 Nov;37(11):1128-39.

60 Susser SR, McCusker J, Belzile E. Comorbidity information in older patients at an emergency visit: self-report vs. administrative data had poor agreement but similar predictive validity. J Clin Epidemiol. 2008 May;61(5):511-5.

61 Leal JR, Laupland KB. Validity of ascertainment of co-morbid illness using administrative databases: a systematic review. Clin Microbiol Infect. 2010 Jun;16(6):715-21.

62 Kieszak SM, Flanders WD, Kosinski AS, Shipp CC, Karp H. A comparison of the Charlson comorbidity index derived from medical record data and administrative billing data. J Clin Epidemiol. 1999 Feb;52(2): $137-42$.

63 Malenka DJ, McLerran D, Roos N, Fisher ES Wennberg JE. Using administrative data to describe casemix: a comparison with the medical record. J Clin Epidemiol. 1994 Sep; 47(9):1027-32.

64 Quan H, Parsons GA, Ghali WA. Validity of information on comorbidity derived from ICD-9-CCM administrative data. Med Care. 2002 Aug;40(8):675-85.

65 Hua-Gen Li M, Hutchinson EA, Tacey M, Duke G. Reliability of comorbidity scores derived from administrative data in the tertiary hospital intensive care setting: a cross-sectional study. BMJ Health Care Inform. 2019 Apr;26(1):e000016.

66 Thygesen SK, Christiansen S, Lash TL, Sørensen HT. The predictive value of ICD-10 diagnostic coding used to assess Charlson comorbidity index conditions in the population-based Danish national registry of patients. BMC Med Res Methodol. 2011 May; 11:83

67 Mo L, Xie Z, Liu G, He Q, Mo Z, Wu Y, et al Feasibility of coding-based Charlson comorbidity index for hospitalized patients in China, a representative developing country. BMC Health Serv Res. 2020 May;20(1):432.

68 Stavem K, Hoel H, Skjaker SA, Haagensen R Charlson comorbidity index derived from chart review or administrative data: agreement and prediction of mortality in intensive care patients. Clin Epidemiol. 2017 Jun;9: $311-20$. 
69 Newschaffer CJ, Bush TL, Penberthy LT. Comorbidity measurement in elderly female breast cancer patients with administrative and medical records data. J Clin Epidemiol. 1997 Jun;50(6):725-33.

70 van Doorn C, Bogardus ST, Williams CS, Concato J, Towle VR, Inouye SK. Risk adjustment for older hospitalized persons: a comparison of two methods of data collection for the Charlson index. J Clin Epidemiol. 2001 Jul;54(7):694-701.

71 Luthi JC, Troillet N, Eisenring MC, Sax H, Burnand B, Quan H, et al. Administrative data outperformed single-day chart review for comorbidity measure. Int J Qual Health Care. 2007 Aug;19(4):225-31.

72 Lee DS, Donovan L, Austin PC, Gong Y, Liu PP, Rouleau GL, et al. Comparison of coding of heart failure and comorbidities in administrative and clinical data for use in outcomes research. Med Care. 2005 Feb;43(2):182-8.

73 Maringe C, Fowler H, Rachet B, Luque-Fernandez MA. Reproducibility, reliability and validity of population-based administrative health data for the assessment of cancer nonrelated comorbidities. PLoS One. 2017 Mar; 12(3): 0172814.

74 Wang CY, Baldwin LM, Saver BG, Dobie SA Green PK, Cai Y, et al. The contribution of longitudinal comorbidity measurements to survival analysis. Med Care. 2009 Jul;47(7): 813-21.

75 Wang PS, Walker A, Tsuang M, Orav EJ, Levin R, Avorn J. Strategies for improving comorbidity measures based on Medicare and Medicaid claims data. J Clin Epidemiol. 2000 Jun;53(6):571-8.

76 Gabriel SE, Crowson CS, O’Fallon WM. A comparison of two comorbidity instruments in arthritis. J Clin Epidemiol. 1999 Dec; 52(12):1137-42.

77 de Boer AZ, Bastiaannet E, Putter H, Marangvan de Mheen PJ, Siesling S, de Munck L, et al. Prediction of other-cause mortality in older patients with breast cancer using comorbidity. Cancers. 2021 Apr;13(7):16-27.

78 Daskivich TJ, Kwan L, Dash A, Grenfield S, Litwin MS. Weighted versus unweighted Charlson score to predict long-term othercause mortality in men with early-stage prostate cancer. Eur Urol. 2014 Dec;66(6):1002-9.

79 Alibhai SMH, Leach M, Tomlinson GA, Krahn MD, Fleshner NE, Naglie G. Is there an optimal comorbidity index for prostate cancer? Cancer. 2008 Mar;112(5):1043-50.

80 Albertsen PC, Fryback DG, Storer BE, Kolon TF, Fine J. The impact of co-morbidity on life expectancy among men with localized prostate cancer. J Urol. 1996 Jul;156(1):127-32.

81 Di Bari M, Virgillo A, Matteuzzi D, Inzitari M, Mazzaglia G, Pozzi C, et al. Predictive validity of measures of comorbidity in older community dwellers: the Insufficienza Cardiaca negli Anziani Residenti a Dicomano Study. J Am Geriatr Soc. 2006 Feb;54(2):210-6.
82 Rochon PA, Katz JN, Morrow LA, McGlinchey-Berroth R, Ahlquist MM, Sarkarati $\mathrm{M}$, et al. Comorbid illness is associated with survival and length of hospital stay in patients with chronic disability. A prospective comparison of three comorbidity indices. Med Care. 1996 Nov;34(11):1093-101.

83 Minol JP, Dimitrova V, Petrov G, Langner R, Boeken U, Rellecke P, et al. The age-adjusted Charlson comorbidity index in minimally invasive mitral valve surgery. Eur J Cardiothorac Surg. 2019 Dec;56(6):1124-30.

84 Atherly A, Fink AS, Campbell DC, Mentzer RM, Henderson W, Khuri S, et al. Evaluating alternative risk-adjustment strategies for surgery. Am J Surg. 2004 Nov;188(5):566-70.

85 Haeuser L, Herzog P, Ayub A, Nguyen DD, Noldus J, Cone EB, et al. Comparison of comorbidity indices for prediction of morbidity and mortality after major surgical procedures. Am J Surg. 2021 Nov;222(5):998-1004.

86 Ash AS, Posner MA, Speckman J, Franco S, Yacht AC, Bramwell L. Using claims data to examine mortality trends following hospitalization for heart attack in Medicare. Health Serv Res. 2003 Oct;38(5):1253-62.

87 Yan Y, Birman-Deych E, Radford MJ, Nilasena DS, Gage BF. Comorbidity indices to predict mortality from medicare data: results from the national registry of atrial fibrillation. Med Care. 2005 Nov;43(11):1073-7.

88 Luchtenborg M, Morris EJA, Tataru D, Coupland VH, Smith A, Milne RL, et al. Investigation of the international comparability of population-based routine hospital data set derived comorbidity scores for patients with lung cancer. Thorax. 2018 Apr;73(4):339-49.

89 Antoniou T, Ng R, Glazier RH, Kopp A, Austin PC. Comparison of comorbidity classification methods for predicting outcomes in a population-based cohort of adults with human immunodeficiency virus infection. Ann Epidemiol. 2014 Jul;24(7):532-7.

90 Fraccaro P, Kontopantelis E, Sperrin M, Peek N, Mallen C, Urban P, et al. Predicting mortality from change-over-time in the Charlson comorbidity index: a retrospective cohort study in a data-intensive UK health system. Medicine. 2016 Oct;95(43):e4973.

91 Frenkel WJ, Jongerius EJ, Mandjes-vanUitert MJ, van Munster BC, de Roij SE. Validation of the Charlson comorbidity index in acutely hospitalized elderly adults: a prospective cohort study. J Am Geriatr Soc. 2014 Feb; 62(2):342-6.

92 Gicas KM, Jones AA, Thornton AE, Petersson A, Livingston E, Waclawik K, et al. Cognitive decline and mortality in a community-based sample of homeless and precariously housed adults: 9-year prospective study. BJPsych Open. 2020 Feb;6(2):e21
93 Rymkiewicz P, Ravani P, Hemmelgarn BR, McAlister FA, Southern DA, Walker R, et al. Effects of longitudinal changes in Charlson comorbidity on prognostic survival model performance among newly diagnosed patients with hypertension. BMC Health Sery Res. 2016 Nov; 16(1):671.

94 Ording AG, Cronin-Fenton DP, Jacobsen JB, Nørgaard M, Thomsen RW, Christiansen $\mathrm{P}$, et al. Comorbidity and survival of Danish breast cancer patients from 20002011: a population-based cohort study. Clin Epidemiol. 2013 Nov;5(Suppl 1):39-46.

95 West DW, Satariano WA, Ragland DR, Hiatt RA. Comorbidity and breast cancer survival: a comparison between black and white women. Ann Epidemiol. 1996 Sep;6(5):4139.

96 Murray SB, Bates DW, Ngo L, Ufberg JW, Shapiro NI. Charlson Index is associated with one-year mortality in emergency department patients with suspected infection. Acad Emerg Med. 2006 May;13(5):530-6.

97 Moro-Sibilot D, Aubert A, Diab S, Lantuejoul S, Fourneret P, Brambilla E, et al. Comorbidities and Charlson score in resected stage I nonsmall cell lung cancer. Eur Respir J. 2005 Sep;26(3):480-6.

98 Huang YQ, Gou R, Diao YS, Yin QH, Fan WX, Liang YP, et al. Charlson comorbidity index helps predict the risk of mortality for patients with type 2 diabetic nephropathy. J Zhejiang Univ Sci B. 2014 Jan;15(1):58-66.

99 Fried L, Bernardini J, Piraino B. Charlson comorbidity index as a predictor of outcomes in incident peritoneal dialysis patients. Am J Kidney Dis. 2001 Feb;37(2): $337-42$.

100 Luben R, Hayat S, Wareham N, Pharoah PP, Khaw KT. Sociodemographic and lifestyle predictors of incident hospital admissions with multimorbidity in a general population, 1999-2019: the EPIC-Norfolk cohort. BMJ Open. 2020 Sep;10(9):e042115.

101 Abdollah F, Sun M, Schmitges J, Thuret R, Djahangirian O, Jeldres C, et al. Development and validation of a reference table for prediction of postoperative mortality rate in patients treated with radical cystectomy: a population-based study. Ann Surg Oncol. 2012 Jan;19(1):309-17.

102 Bhavnani SP, Coleman CI, Guertin D, Yarlagadda RK, Clyne CA, Kluger J. Evaluation of the Charlson comorbidity index to predict early mortality in implantable cardioverter defibrillator patients. Ann Noninvasive Electrocardiol. 2013 Jul;18(4):379-88.

103 Austin SR, Wong YN, Uzzo RG, Beck JR, Egleston BL. Why summary comorbidity measures such as the Charlson comorbidity index and Elixhauser score work. Med Care. 2015 Sep;53(9):e65-72.

104 Sechrest L. Incremental validity: a recommendation. Educ Psychol Meas. 1963 Apr; 23(1):153-8.

105 Fava GA. Forty years of clinimetrics. Psychother Psychosom. 2022;91(1):1-7. 
106 Parks Taylor S, McWilliams A, Taylor BT, Heffner AC, Chou SH, Runyon M, et al. Predictive accuracy of quick sequential organ failure assessment for hospital mortality decreases with increasing comorbidity burden among patients admitted for suspected infection. Crit Care Med. 2019 Aug;47(8): 1081-8.

107 Oh TK, Jeon YT, Do SH, Hwang JW. Preoperative assessment of 30-day mortality risk after major surgery: the role of the quick sequential organ failure assessment: a retrospective observational study. Eur J Anaesthesiol. 2019 Sep;36(9):688-94.

108 Erickson SR, Cole E, Kline-Rogers E, Eagle KA. The addition of the Charlson comorbidity index to the GRACE risk prediction index improves prediction of outcomes in acute coronary syndrome. Popul Health Manag. 2014 Feb;17(1):54-9.

109 Poses RM, McClish DK, Smith WR, Bekes C, Scott WE. Prediction of survival of critically ill patients by admission comorbidity. J Clin Epidemiol. 1996 Jul;49(7):743-7.

110 Ho KM, Finn J, Knuiman M, Webb SAR Combining multiple comorbidities with acute physiology score to predict hospital mortality of critically ill patients: a linked data cohort study. Anaesthesia. 2007 Nov; 62(11):1095-100.

111 Christensen S, Johansen MB, Christiansen $\mathrm{CF}$, Jensen R, Lemeshow S. Comparison of Charlson comorbidity index with SAPS and APACHE scores for prediction of mortality following intensive care. Clin Epidemiol. 2011;3:203-11.

112 Kochar B, Cai W, Cagan A, Ananthakrshnan AN. Frailty is independently associated with mortality in 11,001 patients with inflammatory bowel diseases. Aliment Pharmacol Ther. 2020 Jul;52(2):311-8.

113 Bannay A, Chaignot C, Blotière PO, Basson M, Weill A, Ricordeau P, et al. The best use of the Charlson comorbidity index with electronic health care database to predict mortality. Med Care. 2016 Feb;54(2):18894.

114 Pylvalainen J, Talala K, Murtola T, Taari K, Raitanen J, Tammela TL, et al. Charlson comorbidity index based on hospital episode statistics performs adequately in predicting mortality, but its discriminative ability diminishes over time. Clin Epidemiol. 2019 Oct;11:923-32.

115 Shebeshi DS, Dolja-Gore X, Byles J. Charlson comorbidity index as a predictor of repeated hospital admission and mortality among older women diagnosed with cardiovascular disease. Aging Clin Exp Res. 2021 Oct;33(10):2873-8.

116 Hoang TH, Maiskov VV, Merai IA, Kobalava ZD. Development and validation of a model for predicting 18-month mortality in type 2 myocardial infarction. Am J Emerg Med. 2021 Oct;48:224-30.
117 Radovanovic D, Seifert B, Urban P, Eberli FR, Rickli H, Bertel O, et al. Validity of Charlson comorbidity index in patients hospitalised with acute coronary syndrome. Insights from the nationwide AMIS plus registry 2002-2012. Heart. 2014 Feb;100(4):288-94.

118 Gabler M, Picker N, Geier S, Ley L, Aberle J, Lehrke M, et al. Guideline adherence and associated outcomes in the treatment of type 2 diabetes mellitus patients with an incident cardiovascular comorbidity: an analysis based on a large German claims dataset. Diabetes Ther. 2021 Apr;12(4):1209-26.

119 Newton PJ, Si S, Reid CM, Davidson PM, Hayward CS, Macdonald PS, et al. Survival after an acute heart failure admission. Twelve-month outcomes from the NSW HF snapshot study. Heart Lung Circ. 2020 Jul; 29(7):1032-8.

120 Formiga F, Moreno-Gonzalez R, Chivite D, Franco J, Montero A, Corbella X. High comorbidity, measured by the Charlson comorbidity index, associates with higher 1-year mortality risks in elderly patients experiencing a first acute heart failure hospitalization. Aging Clin Exp Res. 2018 Aug; 30(8):927-33.

121 Akoudad S, Abkenari LD, Schaer BA, Stcherling C, Levy WC, Jordaens L, et al. Comparison of multivariate risk estimation models to predict prognosis in patients with implantable cardioverter defibrillators with or without cardiac resynchronization therapy. Am J Cardiol. 2017 May;119(9):1414-20.

122 Arminanzas C, Fariñas-Alvarez C, Zarauza J, Muñoz P, Ramallo VG, Sellés MM, et al. Role of age and comorbidities in mortality of patients with infective endocarditis. Eur J Intern Med. 2019 Jun;64:63-71.

123 Ho TW, Tsai YJ, Ruan SY, Huang CT, Lai F, $\mathrm{Yu} \mathrm{CJ}$, et al. In-hospital and one-year mortality and their predictors in patients hospitalized for first-ever chronic obstructive pulmonary disease exacerbations: a nationwide population-based study. PLoS One. 2014 Dec;9(12):e114866.

$124 \mathrm{Ng}$ ACC, Chow V, Yong ASC, Chung T, Kritharides L. Prognostic impact of the Charlson comorbidity index on mortality following acute pulmonary embolism. Respiration. 2013 Apr;85(5):408-16.

125 Zoller B, Pirouzifard MN, Sundquist J, Sundquist K. Association of short-term mortality of venous thromboembolism with family history of venous thromboembolism and Charlson comorbidity index. Thromb Haemost. 2019 Jan;119(1):48-55.

126 Holden IK, Lillebaek T, Andersen PH, Wejse C, Johansen IS. Characteristics and predictors for tuberculosis related mortality in Denmark from 2009 through 2014: a retrospective cohort study. PLoS One. 2020 Jun; 15(6): e0231821.

127 Hall RE, Porter J, Quan H, Reeves MJ. Developing an adapted Charlson comorbidity index for ischemic stroke outcome studies. BMC Health Serv Res. 2019 Dec;19(1):930.
128 Han E, Kim TH, Koo H, Yoo J, Heo JH, Nam HS. Heterogeneity in costs and prognosis for acute ischemic stroke treatment by comorbidities. J Neurol. 2019 Mar;266(6):1429-38.

129 Liljehult J, Christensen T, Christensen KB. Early prediction of one-year mortality in ischemic and haemorrhagic stroke. J Stroke Cerebrovasc Dis. 2020 Apr;29(4):104667.

130 Castro HHG, Alencar AP, Benseñor IM, Lotufo PA, Goulart AC. Multimorbidities are associated to lower survival in ischaemic stroke: results from a Brazilian stroke cohort (EMMA study). Cerebrovasc Dis. 2017 Oct; 44(3-4):232-9.

131 Navarro-Cano G, del Rincón I, Pogosian S, Roldán JF, Escalante A. Association of mortality with disease severity in rheumatoid arthritis, independent of comorbidity. Arthritis Rheum. 2003 Sep;48(9):2425-33.

132 Nikiphorou E, de Lusignan S, Mallen C, Roberts J, Khavandi K, Bedarida G, et al. Prognostic value of comorbidity indices and lung diseases in early rheumatoid arthritis: a UK population-based study. Rheumatology. 2020 Jun;59(6):1296-305.

133 Jonsen A, Clarke AE, Joseph L, Belisle P, Bernatski S, Nived O, et al. Association of the Charlson comorbidity index with mortality in systemic lupus erythematosus. Arthritis Care Res. 2011 Sep;63(9):1233-7.

134 Ng YY, Hung YN, Wu SC, Ko PJ, Hwang SM. Progression in comorbidity before hemodialysis initiation is a valuable predictor of survival in incident patients. Nephrol Dial Transplant. 2013 Apr;28(4):1005-12.

135 Chae JW, Song CS, Kim H, Lee KB, Seo BS, Kim DI. Prediction of mortality in patients undergoing maintenance hemodialysis by Charlson comorbidity index using ICD-10 database. Nephron Clin Pract. 2011 Apr; 117(4):c379-84

136 Lin YT, Wu PH, Kuo MC, Lin MY, Lee TC, Chiu YW, et al. High cost and low survival rate in high comorbidity incident elderly hemodialysis patients. PLoS One. 2013 Sep; 8(9):e75318.

137 Rattanasompattikul M, Feroze U, Molnar MZ, Dukkipati R, Kovesdy CP, Nissenson $\mathrm{AR}$, et al. Charlson comorbidity score is a strong predictor of mortality in hemodialysis patients. Int Urol Nephrol. 2012 Dec; 44(6):1813-23.

138 Perez Fernandez M, Martĺnez Miguel PM, Ying H, Haugen CE, Chu NM, Puyol DMR, et al. Comorbidity, frailty, and waitlist mortality among kidney transplant candidates of all ages. Am J Nephrol. 2019 Feb;49(2):10310 .

139 Jassal SV, Schaubel DE, Fenton SS. Baseline comorbidity in kidney transplant recipients: a comparison of comorbidity indices. Am J Kidney Dis. 2005 Jul;46(1):136-42.

140 Javier AD, Figueroa R, Siew ED, Salat $H$, Morse J, Stewart TG, et al. Reliability and utility of the surprise question in CKD stages 4 to 5. Am J Kidney Dis. 2017 Jul;70(1): 93-101. 
141 McArthur E, Bota SE, Sood MM, Nesrallah GE, Kim SJ, Garg AX, et al. Comparing five comorbidity indices to predict mortality in chronic kidney disease: a retrospective cohort study. Can J Kidney Health Dis. 2018 Oct;5:2054358118805418.

142 Miskulin DC, Martin AA, Brown R, Fink NE, Coresh J, Powe NR, et al. Predicting 1 year mortality in an outpatient haemodialysis population: a comparison of comorbidity instruments. Nephrol Dial Transplant. 2004 Feb;19(2):413-20

143 Harvey LA, Toson B, Norris C, Harris IA, Gandy RC, Close JJCT. Does identifying frailty from ICD-10 coded data on hospital admission improve prediction of adverse outcomes in older surgical patients? A population-based study. Age Ageing. 2021 May; 50(3):802-8.

144 Singh M, Rihal CS, Lennon RJ, Spertus JA, Nair KS, Roger VL. Influence of frailty and health status on outcomes in patients with coronary disease undergoing percutaneous revascularization. Circ Cardiovasc Qual Outcomes. 2011 Sep;4(5):496-502.

145 Aasbrenn M, Christiansen CF, Esen BÖ, Suetta C, Nielsen FE. Mortality of older acutely admitted medical patients after early discharge from emergency departments: a nationwide cohort study. BMC Geriatr. 2021 Sep;21(1):410.

146 Meagher AD, Lin A, Mandell SP, Bulger E, Newgard C. A comparison of scoring systems for predicting short- and long-term survival after trauma in older adults. Acad Emerg Med. 2019 Jun;26(6):621-30.

147 Buntinx F, NIclaes L, Suetens C, Jans B, Mertens R, Van den Akker M. Evaluation of Charlson's comorbidity index in elderly living in nursing homes. J Clin Epidemiol. 2002 Nov;55(11):1144-7.

148 van de Vorst IE, Golüke NMS, Vaartjes I, Bots ML, Koek HL. A prediction model for one- and three-year mortality in dementia: results from a nationwide hospital-based cohort of 50,993 patients in the Netherlands. Age Ageing. 2020 Apr;49(3):361-7.

149 Gené Badia J, Borràs Santos A, Contel Segura JC, Terén CA, González LC, Ramírez EL, et al. Predictors of mortality among elderly dependent home care patients. BMC Health Serv Res. 2013 Aug;13:316.

150 Chou WC, Liu KH, Lu CH, Hung YS, Chen MF, Cheng YF, et al. To operate or not: prediction of 3-month postoperative mortality in geriatric cancer patients. J Cancer. 2016 Jan;7(1):14-21.

151 Morris PE, Griffin L, Berry M, Thompson C, Hite RD, Winkelman C, et al. Receiving early mobility during an intensive care unit admission is a predictor of improved outcomes in acute respiratory failure. Am J Med Sci. 2011 May;341(5):373-7.
152 Hadique S, Culp S, Sangani RG, Chapman KD, Khan S, Parker JE, et al. Derivation and validation of a prognostic model to predict 6-month mortality in an intensive care unit population. Ann Am Thorac Soc. 2017 Oct; 14(10):1556-61.

153 Hsu YT, He YT, Ting CK, Tsu MY, Tang GJ, $\mathrm{Pu}$ C. Administrative and claims data help predict patient mortality in intensive care units by logistic regression: a nationwide database study. Biomed Res Int. 2020 Feb; 2020:9076739.

154 Bouamra O, Jacques R, Edwards A, Yates DW, Lawrence T, Jenks T, et al. Prediction modelling for trauma using comorbidity and 'true' 30-day outcome. Emerg Med J. 2015 Dec;32(12):933-8

155 Niven DJ, Kirkpatrick AW, Ball CG, Laupland KB. Effect of comorbid illness on the long-term outcome of adults suffering major traumatic injury: a population-based cohort study. Am J Surg. 2012 Aug;204(2):151-6.

156 Kim DH, Park HC, Cho A, Kim J, Yun KS Kim J, et al. Age-adjusted Charlson comorbidity index score is the best predictor for severe clinical outcome in the hospitalized patients with COVID-19 infection. Medicine. 2021 May;100(18):e25900.

157 Esteban C, Garcia-Gutierrez S, Legarreta MJ, Anton-Ladislao A, Gonzalez N, Lafuente I, et al. One-year mortality in COPD after an exacerbation: the effect of physical activity changes during the event. COPD. 2016 Dec;13(6):718-25

158 Olufajo OA, Reznor G, Lipsitz SR, Cooper ZR, Haider AH, Salim A, et al. Preoperative assessment of surgical risk: creation of a scoring tool to estimate 1-year mortality after emergency abdominal surgery in the elderly patient. Am J Surg. 2017 Apr;213(4): 771-7.e1.

159 Laor A, Tal S, Guller V, Zbar AP, Mavor E. The Charlson comorbidity index (CCI) as a mortality predictor after surgery in elderly patients. Am Surg. 2016 Jan;82(1):22-7.

160 Jeldres C, Isbarn H, Capitanio U, Zini L, Bhojani N, Shariat SF, et al. Development and external validation of a highly accurate nomogram for the prediction of perioperative mortality after transurethral resection of the prostate for benign prostatic hyperplasia. J Urol. 2009 Aug;182(2):626-32.

161 Krousel-Wood MA, Abdoh A, Re R. Comparing comorbid-illness indices assessing outcome variation: the case of prostatectomy. J Gen Intern Med. 1996 Jan;11(1):32-8.

162 Unsal A, Resorlu B, Atmaca AF, Diri A, Gioktug HNG, Can CE, Gok B, et al. Prediction of morbidity and mortality after percutaneous nephrolithotomy by using the Charlson comorbidity index. Urology. 2012 Jan;79(1):55-60.

163 de Souza RC, Pinheiro RS, Coeli CM, Camargo KR. The Charlson comorbidity index (CCI) for adjustment of hip fracture mortality in the elderly: analysis of the importance of recording secondary diagnoses. Cad Saude Publica. 2008 Feb;24(2):315-22.
164 Bell JJ, Pulle RC, Crouch AM, Kuys SS, Ferrier RL, Whitehouse SL. Impact of malnutrition on 12-month mortality following acute hip fracture. ANZ J Surg. 2016 Mar;86(3): $157-61$.

165 Fernandez-Cortinas AB, Campos JV, Paredes-Carnero X, Martinez FM. Is the Charlson comorbidity index a good predictor of mortality and adverse effects in proximal humerus fractures? Orthop Traumatol Surg Res. 2019 Apr;105(2):301-5.

166 Kirkland LL, Kashiwagi DT, Burton MC, Cha S, Varkey P. The Charlson comorbidity index score as a predictor of 30-day mortality after hip fracture surgery. Am J Med Qual. 2011 Nov-Dec;26(6):461-7.

167 Radley DC, Gottlieb DJ, Fisher ES, Tosteson ANA. Comorbidity risk-adjustment strategies are comparable among persons with hip fracture. J Clin Epidemiol. 2008 Jun;61(6): 580-7.

168 Bulow E, Cnudde P, Rogmark C, Rolfson O, Nemes S. Low predictive power of comorbidity indices identified for mortality after acute arthroplasty surgery undertaken for femoral neck fracture. Bone Joint J. 2019 Jan; 101-B(1):104-12.

169 Penfold CM, Whitehouse MR, Blom AW, Judge A, Wilkinson JM, Sayers A. A comparison of comorbidity measures for predicting mortality after elective hip and knee replacement: a cohort study of data from the national joint registry in England and Wales. PLoS One. 2021 Aug;16(8):e0255602.

170 Pares-Badell O, Banqué M, Macià F, Castells $\mathrm{X}$, Sala M. Impact of comorbidity on survival by tumour location: Breast, colorectal and lung cancer (2000-2014). Cancer Epidemiol. 2017 Aug;49:66-74.

171 Young JI, Mongoue-Tchokote S, Wieghard N, Mori M, Vaccaro GM, Sheppard BC, et al Treatment and survival of small-bowel adenocarcinoma in the United States: a comparison with colon cancer. Dis Colon Rectum. 2016 Apr;59(4):306-15.

172 Dobbins TA, Badgery-Parker T, Currow DC, Young JM. Assessing measures of comorbidity and functional status for risk adjustment to compare hospital performance for colorectal cancer surgery: a retrospective data-linkage study. BMC Med Inform Decis Mak. 2015 Jul;15:55.

173 Arostegui I, Gonzalez N, Fernández-de-Larrea N, Lázaro-Aramburu S, Baré M, Redondo $\mathrm{M}$, et al. Combining statistical techniques to predict postsurgical risk of 1-year mortality for patients with colon cancer. Clin Epidemiol. 2018 Mar;10:235-51.

174 van Westreenen HL, Ijpma FF, Wevers KP Afzali H, Patinjn JA. Reoperation after colorectal surgery is an independent predictor of the 1-year mortality rate. Dis Colon Rectum. 2011 Nov;54(11):1438-42.

175 Sarfati D, Tan L, Blakely T, Pearch N. Comorbidity among patients with colon cancer in New Zealand. N Z Med J. 2011 Jul; 124(1338):76-88. 
176 Badic B, Oguer M, Cariou M, Kermarrec T, Bouzeloc S, Nousbaum JP, et al. Prognostic factors for stage III colon cancer in patients 80 years of age and older. Int J Colorectal Dis. 2021 Apr;36(4):811-9.

177 Dekker JW, Gooiker GA, van der Geest LGM, Kolfschoten NE, Struikmans H, Putter $\mathrm{H}$, et al. Use of different comorbidity scores for risk-adjustment in the evaluation of quality of colorectal cancer surgery: does it matter? Eur J Surg Oncol. 2012 Nov; 38(11):1071-8.

178 Shin N, Han EC, Won S, Ryoo SB, Choe EH, Park BK, et al. The prognoses and postoperative outcomes of patients with both colorectal cancer and liver cirrhosis based on a nationwide cohort in Korea. Ann Surg Treat Res. 2020 Aug;99(2):82-9.

179 Krarup PM, Nordholm-Carstensen A, Jorgensen LN, Harling H. Association of comorbidity with anastomotic leak, 30-day mortality, and length of stay in elective surgery for colonic cancer: a nationwide cohort study. Dis Colon Rectum. 2015 Jul;58(7): 668-76.

180 Shia BC, Qin L, Lin KC, Fang CY, Tsai LL, Kao YW, et al. Age comorbidity scores as risk factors for 90-day mortality in patients with a pancreatic head adenocarcinoma receiving a pancreaticoduodenectomy: a national population-based study. Cancer Med. 2020 Jan;9(2):562-74.

181 Guzzo TJ, Dluzniewski P, Orosco R, Platz EA, Partin AW, Han M. Prediction of mortality after radical prostatectomy by Charlson comorbidity index. Urology. 2010 Sep; 76(3):553-7.

182 Lee JY, Kang HW, Rha KH, Cho NH, Choi YD, Hong SJ, et al. Age-adjusted Charlson comorbidity index is a significant prognostic factor for long-term survival of patients with high-risk prostate cancer after radical prostatectomy: a Bayesian model averaging approach. J Cancer Res Clin Oncol. 2016 Apr; 142(4):849-58.

183 Matthes KL, Limam M, Pestoni G, Held L, Korol D, Rohrmann S. Impact of comorbidities at diagnosis on prostate cancer treatment and survival. J Cancer Res Clin Oncol. 2018 Apr;144(4):707-15.

184 Frendl DM, FitzGerald G, Epstein MM, Allison JJ, Sokoloff MH, Ware JE. Predicting the 10-year risk of death from other causes in men with localized prostate cancer using patient-reported factors: development of a tool. PLoS One. 2020 Dec;15(12):e0240039.

185 Daskivich TJ, Chamie K, Kwan L, Labo J, Dash A, Greenfield S. Improved prediction of long-term, other cause mortality in men with prostate cancer. J Urol. 2011 Nov; 186(5):1868-73.

186 Schiffmann J, Gandaglia G, Larcher A, Sun M, Tian Z, Shariat SF, et al. Contemporary 90-day mortality rates after radical cystectomy in the elderly. Eur J Surg Oncol. 2014 Dec;40(12):1738-45.
187 Santos Arrontes D, Fernández-Aceñero MJ, García González JI, Martín Muñoz M, Paniagua Andrés P. Survival analysis of clear cell renal carcinoma according to the Charlson comorbidity index. J Urol. 2008 Mar;179(3): 857-61.

188 Hwang YJ, Minnillo BJ, Kim SP, Abouassaly R. Assessment of healthcare quality metrics: length-of-stay, 30-day readmission, and 30day mortality for radical nephrectomy with inferior vena cava thrombectomy. Can Urol Assoc J. 2015 Mar-Apr;9(3-4):114-21.

189 Boorjian SA, Kim SP, Tollefson MK, Carrasco A, Cheville JC, Thompson RH, et al. Comparative performance of comorbidity indices for estimating perioperative and 5 -year all cause mortality following radical cystectomy for bladder cancer. J Urol. 2013 Jul;190(1):55-60.

190 Froehner M, Koch R, Heberling U, Borkowetz A, Hübler M, Novotny V, et al. Validation of a questionnaire-suitable comorbidity index in patients undergoing radical cystectomy. Urol Int. 2020 Aug; 104(78):567-72.

191 Chang HT, Shi HY, Wang BW, Yeh SCJ. Breast cancer incidence and predictors of surgical outcome: a nationwide longitudinal study in Taiwan. Clin Oncol. 2017 Jun;29(6):362-9.

192 Walz J, Montorsi F, Jeldres C, Suardi N, Shariat SF, Perrotte P, et al. The effect of surgical volume, age and comorbidities on 30day mortality after radical prostatectomy: a population-based analysis of 9208 consecutive cases. BJU Int. 2008 Apr; 101(7):826-32.

193 Marcus MW, Chen Y, Duffy SW, Field JK. Impact of comorbidity on lung cancer mortality: a report from the Liverpool lung project. Oncol Lett. 2015 Apr;9(4):1902-6.

194 Firat S, Bousamra M, Gore E, Byhardt RW. Comorbidity and KPS are independent prognostic factors in stage I non-small-cell lung cancer. Int J Radiat Oncol Biol Phys. 2002 Mar;52(4):1047-57.

195 Deleuran T, Thomsen RW, Nørgaard M, Jacobsen JB, Rasmussen TR, Søgaard M. Comorbidity and survival of Danish lung cancer patients from 2000-2011: a populationbased cohort study. Clin Epidemiol. 2013 Nov;5(Suppl 1):31-8

196 Birim O, Kappetein AP, Bogers AJ. Charlson comorbidity index as a predictor of longterm outcome after surgery for nonsmall cell lung cancer. Eur J Cardiothorac Surg. 2005 Nov;28(5):759-62.

197 Wang CY, Lin YS, Tzao C, Lee HC, Huang $\mathrm{MH}, \mathrm{Hsu} \mathrm{WH}$, et al. Comparison of Charlson comorbidity index and Kaplan-Feinstein index in patients with stage I lung cancer after surgical resection. Eur J Cardiothorac Surg. 2007 Dec;32(6):877-81.

198 Jacobs CD, Mehta K, Gao J, Wang X, Salama JK, Kelsey CR, et al. Nomogram predicting overall survival benefit of stereotactic ablative radiotherapy for early-stage non-small cell lung cancer. Clin Lung Cancer. 2021 Jul; 16:52.
199 Ganti AK, Siedlik E, Marr AS, Loberiza FR Kessinger A. Predictive ability of Charlson comorbidity index on outcomes from lung cancer. Am J Clin Oncol. 2011 Dec;34(6): 593-6.

200 Dhakal P, Shostrom V, Al-Kadhimi ZS, Maness LJ, Gundabolu K, Bhatt VR. Usefulness of Charlson comorbidity index to predict early mortality and overall survival in older patients with acute myeloid leukemia. Clin Lymphoma Myeloma Leuk. 2020 Dec 20(12):804-12.e8.

201 Jung SH, Cho MS, Kim HK, Kim SJ, Kim K, Cheong JW, et al. Risk factors associated with early mortality in patients with multiple myeloma who were treated upfront with a novel agents containing regimen. BMC Cancer. 2016 Aug; 16:613.

202 Kumar A, Graham JE, Resnik L, Karmarkar AM, Deutsch A, Tan A, et al. Examining the association between comorbidity indexes and functional status in hospitalized Medicare fee-for-service beneficiaries. Phys Ther. 2016 Feb;96(2):232-40

203 Multidisciplinary Larynx Cancer Working Group; Mulcahy CF, Mohamed ASR, Kanwar A, Hutcheson KA, Ghosh A, et al. Ageadjusted comorbidity and survival in locally advanced laryngeal cancer. Head Neck. 2018 Sep;40(9):2060-9.

204 de Miguel-Diez J, López-de-Andrés A, Hernández-Barrera V, de Miguel-Yanes JM, Méndez-Bailón M, Muñoz-Rivas N, et al. Influence of COPD on outcomes of patients hospitalized with heart failure: analysis of the Spanish national hospital discharge database (2001-2015). Int J Cardiol. 2018 Oct; 269:213-9.

205 Konig S, Ueberham L, Schuler E, Wiedemann M, Reithmann C, Seyfarth M, et al. Inhospital mortality of patients with atrial arrhythmias: insights from the German-wide helios hospital network of 161,502 patients and 34,025 arrhythmia-related procedures. Eur Heart J. 2018 Nov;39(44):3947-57.

206 Jepma P, Verweij L, Tijssen A, Heymans M, Flierman I, Latour CHM, et al. The performance of the Dutch safety management system frailty tool to predict the risk of readmission or mortality in older hospitalised cardiac patients. BMC Geriatr. 2021 May;21(1): 299.

207 Falsetti L, Viticchi G, Tarquinio N, Silvestrini M, Capeci W, Catozzo V, et al. Charlson comorbidity index as a predictor of inhospital death in acute ischemic stroke among very old patients: a single-cohort perspective study. Neurol Sci. 2016 Sep 37(9):1443-8.

208 Almagro P, Cabrera FJ, Diez J, Boixeda R, Ortiz MBA, Murio C, et al. Comorbidities and short-term prognosis in patients hospitalized for acute exacerbation of COPD: the EPOC en Servicios de medicina interna (ESMI) study. Chest. 2012 Nov; 142(5): 1126-33. 
209 Nguyen MTN, Saito N, Wagatsuma Y. The effect of comorbidities for the prognosis of community-acquired pneumonia: an epidemiologic study using a hospital surveillance in Japan. BMC Res Notes. 2019 Dec;12(1): 817.

210 Ma HM, Tang WH, Woo J. Predictors of inhospital mortality of older patients admitted for community-acquired pneumonia. Age Ageing. 2011 Nov;40(6):736-41.

211 Hao J, Li Y, Zhang X, Pang C, Wang Y, Nigwekar SU, et al. The prevalence and mortality of hyponatremia is seriously underestimated in Chinese general medical patients: an observational retrospective study. BMC Nephrol. 2017 Oct;18(1):328.

212 Ward MM, Pajevic S, Dreyfuss J, Malley JD. Short-term prediction of mortality in patients with systemic lupus erythematosus: classification of outcomes using random forests. Arthritis Rheum. 2006 Feb;55(1): 74-80.

213 Talib S, Sharif F, Manzoor S, Yaqub S, Kashif W. Charlson comorbidity index for prediction of outcome of acute kidney injury in critically ill patients. Iran J Kidney Dis. 2017 Mar;11(2):115-23.

214 Moodley Y. Outcome-specific Charlson comorbidity indices for predicting poor inpatient outcomes following noncardiac surgery using hospital administrative data. Med Care. 2016 Dec;54(12):1082-8.

215 Holler JG, Eriksson R, Jensen TØ, van Wijhe M, Fischer TK, Søgaard OS, et al. First wave of COVID-19 hospital admissions in Denmark: a nationwide population-based cohort study. BMC Infect Dis. 2021 Jan;21(1): 39.

216 Gopaldas RR, Chu D, Dao TK, Huh J, Lemaire SA, Coselli JS, et al. Predictors of surgical mortality and discharge status after coronary artery bypass grafting in patients 80 years and older. Am J Surg. 2009 Nov; 198(5):633-8.

217 Chan LYL, Moran JL, Clarke C, Martin J, Solomon PJ. Mortality and cost outcomes of elderly trauma patients admitted to intensive care and the general wards of an Australian tertiary referral hospital. Anaesth Intensive Care. 2009 Sep;37(5):773-83.

218 Sato M, Tateishi R, Yasunaga H, Horiguchi $\mathrm{H}$, Matsui H, Yoshida H, et al. The ADOPTLC score: a novel predictive index of in-hospital mortality of cirrhotic patients following surgical procedures, based on a national survey. Hepatol Res. 2017 Mar;47(3):E35-43.

219 Neuhaus V, King J, Hageman MG, Ring DC. Charlson comorbidity indices and in-hospital deaths in patients with hip fractures. Clin Orthop Relat Res. 2013 May;471(5):1712-9.

220 Tian Y, Jian Z, Xu B, Liu H. Age-adjusted Charlson comorbidity index score as predictor of survival of patients with digestive system cancer who have undergone surgical resection. Oncotarget. 2017 Oct;8(45):7945361.

Charlson Comorbidity Index
221 Bhandari S, Abdul MKM, Hollabaugh W, Sharma K, Evans DB, Guda N. Decreased trend in hospital mortality from pancreatic cancer despite increase in number of hospital admissions. PLoS One. 2018 Jul;13(7): e0199909.

222 Katna R, Kalyani N, Agarwal S, Singh S, Deshpande A, Bhosale B, et al. Impact of comorbidities on perioperative outcomes for carcinoma of oral cavity. Ann R Coll Surg Engl. 2020 Mar; 102(3):232-5.

223 Tang PL, Lin HS, Hsu CJ. Predicting in-hospital mortality for dementia patients after hip fracture surgery: a comparison between the Charlson comorbidity index (CCI) and the Elixhauser comorbidity index. J Orthop Sci. 2021 May;26(3):396-402.

224 Iezzoni LI, Moskowitz MA. A clinical assessment of MedisGroups. JAMA. 1988 Dec; 260(21):3159-63.

225 Gonnella JS, Hornbrook MC, Louis DZ Staging of disease. A case-mix measurement. JAMA. 1984 Feb;251(5):637-44.

226 Knaus WA, Wagner DP, Draper EA, Zimmerman JE, Bergner M, Bastos PG, et al. The APACHE III prognostic system. Risk prediction of hospital mortality for critically ill hospitalized adults. Chest. 1991 Dec;100(6): 1619-36.

227 Gabbe BJ, Magtengaard K, Hannaford AP, Cameron PA. Is the Charlson comorbidity Index useful for predicting trauma outcomes? Acad Emerg Med. 2005 Apr;12(4): 318-21.

228 Elixhauser A, Steiner C, Harris DR, Coffey RM. Comorbidity measures for use with administrative data. Med Care. 1998 Jan;36(1): 8-27.

229 Moore L, Lavoie A, Le Sage N, É Bergeron, Émond M, Liberman M, et al. Using information on preexisting conditions to predict mortality from traumatic injury. Ann Emerg Med. 2008 Oct;52(4):356-64.e2.

230 Kim CY, Sivasundaram L, LaBelle MW, Trivedi NN, Liu RW, Gillespie RJ. Predicting adverse events, length of stay, and discharge disposition following shoulder arthroplasty: a comparison of the Elixhauser comorbidity measure and Charlson comorbidity index. J Shoulder Elbow Surg. 2018 Oct;27(10):1748-55.

231 Stukenborg GJ, Wagner DP, Connors AF. Comparison of the performance of two comorbidity measures, with and without information from prior hospitalizations. Med Care. 2001 Jul;39(7):727-39.

232 Southern DA, Quan H, Ghali WA. Comparison of the Elixhauser and Charlson/Deyo methods of comorbidity measurement in administrative data. Med Care. 2004 Apr; 42(4):355-60.

233 Ladha KS, Zhao K, Quraishi SA, Kurth T, Eikermann M, Kaafarani HMA, et al. The Deyo-Charlson and Elixhauser-van Walraven comorbidity indices as predictors of mortality in critically ill patients. BMJ Open. 2015 Sep;5(9):e008990.
234 Gilbert EA, Krafty RT, Bleicher RJ, Egleston BL. On the use of summary comorbidity measures for prognosis and survival treatment effect estimation. Health Serv Outcomes Res Methodol. 2017 Dec;17(3-4):237-55.

235 Quan H, Li B, Couris M, Fushimi K, Graham $\mathrm{P}$, Hider $\mathrm{P}$, et al. Updating and validating the Charlson comorbidity index and score for risk adjustment in hospital discharge abstracts using data from 6 countries. Am J Epidemiol. 2011 Mar;173(6):676-82.

236 Klabunde CN, Potosky AL, Legler JM, Warren JL. Development of a comorbidity index using physician claims data. J Clin Epidemiol. 2000 Dec;53(12):1258-67.

237 Schneeweiss S, Wang PS, Avorn J, Jlynn RJ. Improved comorbidity adjustment for predicting mortality in Medicare populations. Health Serv Res. 2003 Aug;38(4):1103-20.

238 Von Korff M, Wagner EH, Saunders K. A chronic disease score from automated pharmacy data. J Clin Epidemiol. 1992 Feb;45(2): 197-203.

239 Charlson ME, Ales KL, Simon R, MacKenzie $\mathrm{CR}$. Why predictive indexes perform less well in validation studies. Is it magic or methods? Arch Intern Med. 1987 Dec; 147(12):2155-61.

240 Hall SF. A user's guide to selecting a comorbidity index for clinical research. J Clin Epidemiol. 2006 Aug;59(8):849-55.

241 Fava GA, Tomba E, Tossani E. Innovative trends in the design of therapeutic trials in psychopharmacology and psychotherapy. Prog Neuropsychopharmacol Biol Psychiatry. 2013 Jan;40:306-11.

242 Strauss VY, Jones PW, Kadam UT, Jordan KP. Distinct trajectories of multimorbidity in primary care were identified using latent class growth analysis. J Clin Epidemiol. 2014 Oct;67(10):1163-71.

243 Nicholson K, Almirall J, Fortin M. The measurement of multimorbidity. Health Psychol. 2019 Sep;38(9):783-90.

244 Diederichs C, Berger K, Bartels DB. The measurement of multiple chronic diseases: a systematic review on existing multimorbidity indices. J Gerontol A Biol Sci Med Sci. 2011 Mar;66(3):301-11.

245 Valderas JM, Mercer SW, Fortin M. Research on patients with multiple health conditions: different constructs, different views, one voice. J Comorb. 2011 Dec;1:1-3.

246 Huntley AL, Johnson R, Purdy S, Valderas JM, Salisbury C. Measures of multimorbidity and morbidity burden for use in primary care and community settings: a systematic review and guide. Ann Fam Med. 2012 MarApr;10(2):134-41.

247 Brusselaers N, Lagergren J. The Charlson comorbidity index in registry-based research. Methods Inf Med. 2017;56(5):401-6.

248 Yurkovich M, Avina-Zubieta JA, Thomas J, Gorenchtein M, Lacaille D. A systematic review identifies valid comorbidity indices derived from administrative health data. J Clin Epidemiol. 2015 Jan;68(1):3-14. 
249 Sharabiani MT, Aylin P, Bottle A. Systematic review of comorbidity indices for administrative data. Med Care. 2012 Dec; 50(12):1109-18.

250 Carrozzino D, Patierno C, Guidi J, Berrocal Montiel C, Cao J, Charlson ME, et al. Clinimetric criteria for patient-reported outcome measures. Psychother Psychosom. 2021 Jun; 90(4):222-32.

251 Naessens JM, Leibson CL, Krishan I, Ballard DJ. Contribution of a measure of disease complexity (COMPLEX) to prediction of outcome and charges among hospitalized patients. Mayo Clin Proc. 1992 Dec;67(12): 1140-9.

252 Iezzoni LI, Ash AS, Shwartz M, Daley J, Hughes JS, Mackiernan YD. Predicting who dies depends on how severity is measured: implications for evaluating patient outcomes. Ann Intern Med. 1995 Nov; 123(10): 763-70.

253 Poses RM, Smith WR, McClish DK, Anthony M. Controlling for confounding by indication for treatment. Are administrative data equivalent to clinical data? Med Care. 1995 Apr;33(4 Suppl):AS36-46.

254 Iezzoni LI, Ash AS, Shwartz M, Daley J, Hughes JS, Mackiernan YD. Judging hospitals by severity-adjusted mortality rates: the influence of the severity-adjustment method. Am J Public Health. 1996 Oct;86(10): 1379-87.

255 Young WW, Kohler S, Kowalski J. PMC patient severity scale: derivation and validation. Health Serv Res. 1994 Aug;29(3):36790.

256 Bateman BT, Mhyre GM, Hernandez-Diaz S, Huybrechts KF, Fischer MA, Creanga AA, et al. Development of a comorbidity index for use in obstetric patients. Obstet Gynecol. 2013 Nov; 122(5):957-65.

257 Incalzi RA, Capparella O, Gemma A, Landi F, Bruno E, Di Meo F, et al. The interaction between age and comorbidity contributes to predicting the mortality of geriatric patients in the acute-care hospital. J Intern Med. 1997 Oct;242(4):291-8.

258 van Walraven C, Austin PC, Jennings A, Quan H, Forster AJ. A modification of the Elixhauser comorbidity measures into a point system for hospital death using administrative data. Med Care. 2009 Jun;47(6): 626-33.

259 Gagne JJ, Glynn RJ, Avorn J, Levin R, Schneeweiss S. A combined comorbidity score predicted mortality in elderly patients better than existing scores. J Clin Epidemiol. 2011 Jul;64(7):749-59.

260 Sharma N, Schwendimann R, Endrich O, Ausserhofer D, Simon M. Comparing Charlson and Elixhauser comorbidity indices with different weightings to predict inhospital mortality: an analysis of national inpatient data. BMC Health Serv Res. 2021 Jan;21(1):13.
261 Iezzoni LI, Shwartz M, Ash AS, Hughes JS, Daley J, Mackierman YD. Severity measurement methods and judging hospital death rates for pneumonia. Med Care. 1996 Jan; 34(1):11-28.

262 Armitage JN, van der Meulen JH; Royal College of Surgeons Co-Morbidity Consensus Group. Identifying co-morbidity in surgical patients using administrative data with the Royal College of Surgeons Charlson Score. Br J Surg. 2010 May;97(5):772-81.

263 Bottle A, Aylin P. Comorbidity scores for administrative data benefited from adaptation to local coding and diagnostic practices. J Clin Epidemiol. 2011 Dec;64(12):1426-33.

264 Bravo G, Dubois MF, Hébert R, De Wals P, Messier L. A prospective evaluation of the Charlson comorbidity index for use in longterm care patients. J Am Geriatr Soc. 2002 Apr:50(4):740-5.

265 Desai MM, Bogardus ST, Williams CS, Vitagliano G, Inouye SK. Development and validation of a risk-adjustment index for older patients: the high-risk diagnoses for the elderly scale. J Am Geriatr Soc. 2002 Mar; 50(3):474-81.

266 Kusumastuti S, Gerds TA, Lund R, Mortensen EL, Westendorp RGJ. Discrimination ability of comorbidity, frailty, and subjective health to predict mortality in community-dwelling older people: Population based prospective cohort study. Eur J Intern Med. 2017 Jul;42:29-38.

267 Reid BC, Alberg AJ, Klassen AC, Rozier RG, Garcia I, Winn DM, et al. A comparison of three comorbidity indexes in a head and neck cancer population. Oral Oncol. 2002 Feb;38(2):187-94

268 Volk ML, Hernandez JC, Lok AS, Marrero JA. Modified Charlson comorbidity index for predicting survival after liver transplantation. Liver Transpl. 2007 Nov;13(11): 1515-20.

269 Martins M, Blais R. Evaluation of comorbidity indices for inpatient mortality prediction models. J Clin Epidemiol. 2006 Jul;59(7): 665-9.

270 Baldwin LM, Klabunde CN, Green P, Barlow $\mathrm{W}, \mathrm{Wright} \mathrm{G}$. In search of the perfect comorbidity measure for use with administrative claims data: does it exist? Med Care. 2006 Aug;44(8):745-53.

271 Toson B, Harvey LA, Close JC. The ICD-10 Charlson comorbidity index predicted mortality but not resource utilization following hip fracture. J Clin Epidemiol. 2015 Jan; 68(1):44-51.

272 Hallstrom AP, Cobb LA, Yu BH. Influence of comorbidity on the outcome of patients treated for out-of-hospital ventricular fibrillation. Circulation. 1996 Jun;93(11):201922.

273 Cornoni-Huntley JC, Foley DJ, Guralnik JM. Co-morbidity analysis: a strategy for understanding mortality, disability and use of health care facilities of older people. Int J Epidemiol. 1991;20(Suppl 1):S8-17.
274 Fillenbaum GG, Pieper CF, Cohen HJ, Cornoni-Huntley JC, Guralnik JM. Comorbidity of five chronic health conditions in elderly community residents: determinants and impact on mortality. J Gerontol A Biol Sci Med Sci. 2000 Feb;55(2):M84-9.

275 Satariano WA, Ragland DR. The effect of comorbidity on 3-year survival of women with primary breast cancer. Ann Intern Med. 1994 Jan;120(2):104-10.

276 Khan IH, Catto JR, Edward N, Fleming LW, Henderson IS, MacLeod AM. Influence of coexisting disease on survival on renal-replacement therapy. Lancet. 1993 Feb; 341(8842):415-8

277 Davies SJ, Phillips L, Naish PF, Russell GI Quantifying comorbidity in peritoneal dialysis patients and its relationship to other predictors of survival. Nephrol Dial Transplant. 2002 Jun;17(6):1085-92.

278 van Manen JG, Korevaar JC, Dekker FW, Boeschoten EW, Bossuyt PMM, Krediet RT, et al. How to adjust for comorbidity in survival studies in ESRD patients: a comparison of different indices. Am J Kidney Dis. 2002 Jul;40(1):82-9.

279 Liu J, Huang Z, Gilbertson DT, Foley RN, Collins AJ. An improvbed comorbidity index for outcome analyses among dialysis patients. Kidney Int. 2010 Jan;77(2):141-51.

280 Rius C, Pérez G, Martínez JM, Bares M, Schiaffino A, Gispert R, et al. An adaptation of Charlson comorbidity index predicted subsequent mortality in a health survey. J Clin Epidemiol. 2004 Apr;57(4):403-8.

281 Colinet B, Jacot W, Bertrand D, Lacombe S, Bozonnat M-C, Daurès J-P, et al. A new simplified comorbidity score as a prognostic factor in non-small-cell lung cancer patients: description and comparison with the Charlson's index. Br J Cancer. 2005 Nov; 93(10):1098-105.

282 Sessler DI, Sigl JC, Manberg PJ, Kelley SD, Schubert A, Chamoun NG. Broadly applicable risk stratification system for predicting duration of hospitalization and mortality. Anesthesiology. 2010 Nov;113(5):1026-37.

283 Holman CDJ, Preen DB, Baynham NJ, Finn JC, Semmens JB. A multipurpose comorbidity scoring system performed better than the Charlson index. J Clin Epidemiol. 2005 Oct; 58(10):1006-14

284 Newman AB, Boudreau RM, Naydeck BL Fried LF, Harris TB. A physiologic index of comorbidity: relationship to mortality and disability. J Gerontol A Biol Sci Med Sci. 2008 Jun;63(6):603-9.

285 Fan VS, Au D, Heagerty P, Deyo RA, McDonell MB, Fihn SD. Validation of case-mix measures derived from self-reports of diagnoses and health. J Clin Epidemiol. 2002 Apr;55(4):371-80.

286 Byles JE, D’Este C, Parkinson L, O'Connell $\mathrm{R}$, Treloar C. Single index of multimorbidity did not predict multiple outcomes. J Clin Epidemiol. 2005 Oct;58(10):997-1005. 
287 Austin PC, van Walraven C, Wodchis WP, Newman A, Anderson JM. Using the Johns Hopkins aggregated diagnosis groups (ADGs) to predict mortality in a general adult population cohort in Ontario, Canada. Med Care. 2011 Oct;49(10):932-9.

288 Austin PC, Shah BR, Newman A, Anderson JM. Using the Johns Hopkins' aggregated diagnosis groups (ADGs) to predict 1-year mortality in population-based cohorts of patients with diabetes in Ontario, Canada. Diabet Med. 2012 Sep;29(9):1134-41.

289 England BR, Sayles H, Mikuls TR, Johnson DS, Michaud K. Validation of the rheumatic disease comorbidity index. Arthritis Care Res. 2015 May;67(6):865-72.

290 Tooth L, Hockei R, Byles J, Dobson A. Weighted multimorbidity indexes predicted mortality, health service use, and health-related quality of life in older women. J Clin Epidemiol. 2008 Feb;61(2):151-9.

291 Fleming ST, Pearce KA, McDavid K, Pavlov $\mathrm{D}$. The development and validation of a comorbidity index for prostate cancer among Black men. J Clin Epidemiol. 2003 Nov; 56(11):1064-75.

292 Sorror ML, Maris MB, Storb R, Baron F, Sandmaier BM, Maloney DG, et al. Hematopoietic cell transplantation (HCT)-specific comorbidity index: a new tool for risk assessment before allogeneic HCT. Blood. 2005 Oct;106(8):2912-9.

293 Sorror ML, Storb RF, Sandmaier BM, Maziarz RT, Pulsipher MA, Maris MB, et al. Comorbidity-age index: a clinical measure of biologic age before allogeneic hematopoietic cell transplantation. J Clin Oncol. 2014 Oct; 32(29):3249-56.

294 Vaughn JE, Storer BE, Armand P, Raimondi R, Gibson C, Rambaldi A, et al. Design and validation of an augmented hematopoietic cell transplantation-comorbidity index comprising pretransplant ferritin, albumin, and platelet count for prediction of outcomes after allogeneic transplantation. Biol Blood Marrow Transplant. 2015 Aug;21(8): 1418-24.

295 Clark DO, Von Korff M, Saunders K, Baluch WM, Simon GE. A chronic disease score with empirically derived weights. Med Care. 1995 Aug;33(8):783-95.
296 George J, Vuong T, Bailey MJ, Kong DC, Marriott JL, Stewart K. Development and validation of the medication-based disease burden index. Ann Pharmacother. 2006 Apr;40(4):645-50.

297 Linn BS, Linn MW, Gurel L. Cumulative illness rating scale. J Am Geriatr Soc. 1968 May;16(5):622-6.

298 Gurel L, Linn MW, Linn BS, Davis JE, Maroney RJ. Patients in nursing homes. Multidisciplinary characteristics and outcomes. JAMA. 1970 Jul;213(1):73-7.

299 Extermann M, Overcash J, Lyman GH, Parr J, Balducci L. Comorbidity and functional status are independent in older cancer patients. J Clin Oncol. 1998 Apr;16(4):1582-7.

300 Parmelee PA, Thuras PD, Katz IR, Lawton MP. Validation of the cumulative illness rating scale in a geriatric residential population. J Am Geriatr Soc. 1995 Feb;43(2):130-7.

301 Mulrow CD, Gerety MB, Cornell JE, Lawrence VA, Kanten DN. The relationship between disease and function and perceived health in very frail elders. J Am Geriatr Soc. 1994 Apr;42(4):374-80.

302 Liu M, Domen K, Chino N. Comorbidity measures for stroke outcome research: a preliminary study. Arch Phys Med Rehabil. 1997 Feb;78(2):166-72.

303 Liu M, Tsuji T, Tsujiuchi K, Chino N. Comorbidities in stroke patients as assessed with a newly developed comorbidity scale. Am J Phys Med Rehabil. 1999 Sep-Oct; 78(5):416-24.

304 Groll DL, Heyland DK, Caeser M, Wright JG. Assessment of long-term physical function in acute respiratory distress syndrome (ARDS) patients: comparison of the Charlson Comorbidity Index and the Functional Comorbidity Index. Am J Phys Med Rehabil. 2006 Jul;85(7):574-81.

305 Harse JD, Holman CD. Charlson's index was a poor predictor of quality of life outcomes in a study of patients following joint replacement surgery. J Clin Epidemiol. 2005 Nov; 58(11):1142-9.

306 Tessier A, Finch L, Daskalopoulou SS, Mayo NE. Validation of the Charlson Comorbidity Index for predicting functional outcome of stroke. Arch Phys Med Rehabil. 2008 Jul; 89(7):1276-83.
307 Greenfield S, Apolone G, McNeil BJ, Cleary $\mathrm{PD}$. The importance of co-existent disease in the occurrence of postoperative complications and one-year recovery in patients undergoing total hip replacement. Comorbidity and outcomes after hip replacement. Med Care. 1993 Feb;31(2):141-54.

308 Imamura K, McKinnon M, Middleton R, Black N. Reliability of a comorbidity measure: the index of co-existent disease (ICED). J Clin Epidemiol. 1997 Sep;50(9):1011-6.

309 Chen AY, Daley J, Thibault GE. Angina patients' ratings of current health and health without angina: associations with severity of angina and comorbidity. Med Decis Making. 1996 Apr-Jun;16(2):169-77.

310 Parkerson GR, Broadhead WE, Tse CK. The Duke Severity of Illness Checklist (DUSOI) for measurement of severity and comorbidity. J Clin Epidemiol. 1993 Apr;46(4):37993.

311 Parkerson GR, Michener JL, Wu LR, Finch JN, Muhlbaier LH, Magruder-Habib K, et al. Associations among family support, family stress, and personal functional health status. J Clin Epidemiol. 1989 Jan;42(3):217-29.

312 Rozzini R, Frisoni GB, Ferrucci L, Barbisoni P, Sabatino T, Ranieri P, et al. Geriatric index of comorbidity: validation and comparison with other measures of comorbidity. Age Ageing. 2002 Jul;31(4):277-85.

313 Zekry D, Valle BHL, Michel JP, Esposito F, Gold G, Krause KH, et al. Prospective comparison of six co-morbidity indices as predictors of 5 years post hospital discharge survival in the elderly. Rejuvenation Res. 2010 Dec;13(6):675-82.

314 Crabtree HL, Gray CS, Hildreth AJ, O'Connell JE, Brown J. The comorbidity symptom scale: a combined disease inventory and assessment of symptom severity. J Am Geriatr Soc. 2000 Dec;48(12):1674-8.

315 Bayliss EA, Ellis JL, Steiner JF. Subjective assessments of comorbidity correlate with quality of life health outcomes: initial validation of a comorbidity assessment instrument. Health Qual Life Outcomes. 2005 Sep; 3:51.

316 Verbrugge LM, Lepkowski JM, Imanaka Y. Comorbidity and its impact on disability. Milbank Q. 1989;67(3-4):450-84. 